\title{
A novel approach to the detection of unusual mitochondrial protein change suggests hypometabolism of ancestral simians
}

Bala Anı Akpınar ${ }^{1}$, Vivek Sharma ${ }^{1,2}$, Cory D. Dunn ${ }^{1}$

${ }^{1}$ Institute of Biotechnology, University of Helsinki, Helsinki, 00014, Finland

${ }^{2}$ Department of Physics, University of Helsinki, Helsinki, 00014, Finland

Corresponding author:

Cory Dunn, Ph.D.

P.O. Box 56

University of Helsinki

00014 Finland

Email: cory.dunn@helsinki.fi

Phone: +358 503119307 


\begin{abstract}
1 Abstract:
3 The mitochondrial genome encodes core subunits of the oxidative phosphorylation machinery, 4 and it is expected that these mitochondria-encoded polypeptides would be shaped by 5 bioenergetic needs corresponding to diverse diets and environments. Here, we have 6 developed a robust and effective method for highlighting phylogenetic tree edges with 7 unexpectedly rapid, and likely efficacious, mitochondrial protein evolution. Further, our 8 approach allows detection of those discrete protein substitutions likely to alter enzyme 9 performance. A survey of mammalian taxonomic groups performed using our method supports 10 the idea that widely conserved residues in mitochondria-encoded proteins are more likely to 11 rapidly mutate within specific clades. Intriguingly, primates share a substitution profile with a 12 number of mammals characterized by low mass-specific rates of metabolism. Our data 13 suggest low metabolic performance and activity of ancestral simians, as well as reduced 14 cellular metabolism across many extant primates.
\end{abstract}




\section{Introduction:}

Mitochondria are derived from an ancestral endosymbiont related to alphaproteobacteria (Bonen et al. 1977; Roger et al. 2017). While most of the genes encoded by the pre-mitochondrial endosymbiont were lost or transferred to the (proto-)nucleus, a handful of protein-coding genes continue to reside upon a mitochondrial genome that is inherited maternally in vertebrates (Hoekstra 2000; Christie and Beekman 2017). The mitochondrial DNA (mtDNA) of mammals typically encodes 22 transfer RNAs, 2 ribosomal RNAs, and 13 proteins that are crucial for the process of oxidative phosphorylation (OXPHOS) (Gustafsson et al. 2016). Mitochondria-encoded proteins, along with numerous proteins encoded by nuclear DNA, meet at the mitochondrial inner membrane to form the complexes and super-complexes that drive OXPHOS (Pfanner et al. 2019). In cells engaged in mitochondrial ATP production, Complexes I through IV convert energy derived from food into a proton gradient across the mitochondrial inner membrane. Complex $\mathrm{V}$ takes advantage of this proton gradient to synthesize ATP (Sousa et al. 2018).

It is not surprising that many amino acid positions found within core OXPHOS complex components are well conserved (Nachman et al. 1996; Nachman 1998; Stewart et al. 2008; da Fonseca et al. 2008), given the fundamental role of these proteins in cellular bioenergetics. However, against this background of high protein conservation, changes have been identified within particular clades that may be linked to their bioenergetic needs. Unexpected substitutions to mtDNA-encoded proteins that might be associated with transitions in environment or physiology have been identified within multiple vertebrates (Garvin et al. 2015), including bats (Shen et al. 2010), primates (Pierron et al. 2012), hummingbirds (Dunn et al. 2020), 'high-performance' fish (Dalziel et al. 2006), snakes (Castoe et al. 2008), and aquatic mammals (McClellan et al. 2005).

Here, we have developed a straightforward and computationally undemanding method that can highlight phylogenetic tree edges and polypeptides characterized by greater-thanexpected, potentially efficacious change to conserved amino acid positions. We have applied our approach to the full set of mammalian reference mtDNAs at multiple taxonomic levels, and we found that specific groups tend to be enriched for mutations at highly conserved sites. Primates clearly possess an elevated propensity for substitution at key locations within mitochondria-encoded proteins, and our analysis also indicates that ancestral simians were likely to be characterized by low mass-independent metabolic rates. 


\section{Results:}

Toward a comprehensive analysis of mitochondrial protein evolution in mammals, we recovered full GenBank records for mammalian mtDNAs stored in the RefSeq database (O'Leary et al. 2016). The mtDNA record for the reptile Anolis punctatus was also retrieved for the purpose of rooting a mammalian phylogenetic tree. Coding sequences were extracted and concatenated, a practice consistent with uniparental inheritance and co-evolution of vertebrate mtDNA-encoded polypeptides (Sato and Sato 2017). Concatenated protein-coding sequences were aligned using MAFFT (Katoh and Standley 2013), and phylogenetic tree inference was performed using RAxML-NG (Kozlov et al. 2019). Next, we used the PAGAN package (Löytynoja et al. 2012) to reconstruct the amino acid character values of each position at all bifurcating nodes within our maximum likelihood mtDNA tree. Output protein alignments from PAGAN were ungapped using Bos taurus protein sequences as a reference. Using the tree and node character values emerging from PAGAN, we inferred all amino acid substitutions at positions for which less than $2 \%$ of extant and ancestral sequences contained gaps (Supplemental File 1). Taxonomic information for each input sequence was recovered from the National Center for Biotechnology Information (NCBI) (Schoch et al. 2020), and taxonomic information at internal nodes was assigned by concordant annotation of all descendent external tree nodes at each selected taxonomic level. The resulting taxonomic dataset was then linked to each analyzed tree edge and amino acid substitution.

Using our table of mitochondrial protein substitutions, we determined the relative conservation of each analyzed amino acid position by calculating a total substitution score (TSS, Figure 1a), which is simply the sum of substitution events mapped to a given alignment position across all tree edges. This 'tree-aware' metric may surpass measures of conservation that consider positional character frequencies extracted from multiple sequence alignments, since these character frequencies are sensitive to sampling biases. The dynamic range of TSSs is potentially unlimited and can take advantage of the continuous accretion of new sequence information. When plotting the TSSs of each analyzed position across mtDNAencoded proteins, it is clear that the vast majority of these mitochondria-encoded amino acids are conserved and seldom change over roughly 200 million years of mammal evolution (Figure 1b). Indeed, the median TSS of analyzed positions is nine, the TSS at the 25th percentile is one, and the TSS at the 75th percentile is 56 . However, a smaller subset of aligned, sparsely gapped positions were quite accepting of substitutions, and the maximum TSS across all analyzed mtDNA-encoded amino acid positions is 361 . TSS values for each mitochondrial protein position, calculated from the mammalian dataset and indexed using the Bos taurus reference sequence, are provided as Supplemental File 2.

We then extended our analysis to highlight those specific tree edges where more substantive change to mammalian mtDNA-encoded proteins had occurred than would be expected based upon the overall level of nucleotide divergence (Figure 1c). Substitutions at a position with a high TSS (low conservation) and those occurring at a position with a low TSS (high conservation) might be expected to have effects of differing magnitude, so any approach 
highlighting unexpected and efficacious protein evolution along an edge should take into account both the number and the potential effect of substitutions. Toward this goal, we recovered the TSS for each substituted position along a tree edge, added 1, calculated the reciprocal, and summed these reciprocal values in order to generate a substantive protein change sum (SPCS). A subset of tree edges were clearly associated with an elevated SPCS when considering all analyzed positions within mtDNA-encoded proteins. We then compared the SPCS of an edge to the nucleotide divergence along that edge, as represented by the tree branch length $(\mathrm{BL})$ emerging from our PAGAN analysis. Only edges with BLs averaging less than 0.2 substitutions per site were included within this regression analysis (Figure 1d), and longer edges were discarded. When plotting SPCSs against BLs, we encountered a linear relationship (R-squared of 0.32 ) between SPCS and BL, with most tree edges (69\%) falling below the regression line. When plotting SPCS residuals for each tree edge, residual magnitude appeared to scale with $\mathrm{BL}$ (Figure 1e), as might be expected if longer divergence times provide a greater opportunity for the accumulation of functionally neutral substitutions or of substitutions with potential effects on OXPHOS. Consequently, we calculated the arctangent (expressed in radians) of the SPCS residual divided by the BL, so that we might more meaningfully compare SPCSs from edges of low BL with edges of high $B L$. The resulting angle $\left(\theta_{\text {evo }}\right)$ is a measure of protein change suggestive of functional relevance.

Clearly, a number of edges exhibit a substantially elevated value of $\theta_{\text {evo }}$ when considering all mtDNA-encoded amino acid positions analyzed together (Figure 1f), or when analyzing individual respiratory complexes (Supplemental Figure S1). Demonstrating the utility of our approach, we encountered edges leading to several domesticated species among those with the highest $\theta_{\text {evo }}$ scores calculated across all subunits: Bos taurus (cattle), Sus scrofa (pig), and Ovis aries (sheep) were ranked first, seventh, and eighth of 2329 edges for which a $\theta_{\text {evo }}$ value was calculated (Supplemental File 3 ). These findings likely correspond with adaptation to the needs of their human captors or with potential population bottlenecks encountered during domestication (Larson and Fuller 2014; Bortoluzzi et al. 2020). Edges leading to several vulnerable or endangered species (IUCN 2008a; b, 2016a; b) are also commonly found within the top-ten ranked edges with respect to $\theta_{\text {evo }}$ calculated across all subunits, including Gorilla gorilla (western gorilla), Ursus thibetanus mupinensis (Asian black bear, Sichuan subspecies), Budorcas taxicolor (takin), and Panthera tigris amoyensis (South China tiger). These data are consistent with population bottlenecks that allow persistence of unusual and potentially deleterious substitutions (Ohta 1973). Unusual substitutions at polypeptide positions that are, with the exception of the indicated edge, totally conserved among mammals contribute greatly to the high $\theta_{\text {evo }}$ rank of these edges (Supplemental File 1). Our full $\theta_{\text {evo }}$ dataset, as well as the matching inferred substitutions, should serve as a valuable resource for those studying the evolution of mitochondrial proteins within specific mammalian groups, as well as their ancestors and kin.

After calculating the $\theta_{\text {evo }}$ values along each edge, we asked whether particular clades might harbor an unusual number of edges along which a considerable measure of potentially efficacious protein change had occurred. Toward this goal, we calculated the median $\theta_{\text {evo }}$ for 
orders assigned five or more edges. Although orders typically encompassed edges with a wide diversity of $\theta_{\text {evo }}$ values (Figure $2 a$ ), several orders were clearly characterized by greater-thanexpected median $\theta_{\text {evo }}$ values. The three orders with the highest median $\theta_{\text {evo }}$ values were Proboscidea (encompassing elephants and mammoths), Pilosa (sloths and anteaters), and Primates (including monkeys, apes, lemurs, and lorises), while the three orders with the lowest median $\theta_{\text {evo }}$ values were Perissodactyla (odd-toed ungulates), Artiodactyla (even-toed ungulates), and Lagomorpha (rabbits, hares, and pika). Lower boundaries of the $90 \%$ confidence interval of the median $\theta_{\text {evo }}$ (Figure $2 b$ ) further indicated that rapid and substantive protein evolution was occuring within the mitochondria of Primates and Pilosa, while the upper boundaries of the $90 \%$ confidence interval of the median $\theta_{\text {evo }}$ (Figure $2 \mathrm{c}$ ) supported constrained evolution of mitochondrial proteins in Artiodactyla, Lagomorpha, and Perissodactyla. Similar outcomes emerged during analysis of individual OXPHOS complexes (Supplemental Figures S2 and S3)

A comparable evaluation was performed for mammalian families. As seen during our analysis of mammalian orders, some families exhibited widespread, rapid protein evolution at more conserved positions, while the opposite held true for other families. Here, Bradypodidae (three-toed sloths), Cercopithecidae (Old World monkeys), and Octodontidae (encompassing degus, rock rats, and viscacha rats) were associated with the three highest median $\theta_{\text {evo }}$ values (Figure 3a), while Equidae (horses and related animals), Leporidae (rabbits and hares), and

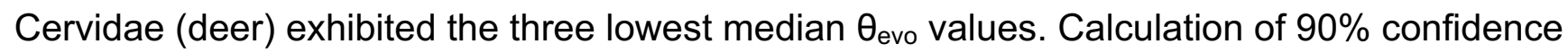
intervals supported the ranking of families obtained by analysis of median $\theta_{\text {evo }}$ values (Figures $3 \mathrm{~b}$ and $3 \mathrm{c}$ ). Analysis of individual OXPHOS complexes signalled similar divergence in the magnitude of protein evolution among families (Supplemental Figures S4, S5, and S6).

Given the abundance of mitochondrial protein evolution found among primates, we focused additional attention upon this clade by examining the trend among primate suborders, infraorders, subfamilies, and genera. At the rank of suborder, Haplorrhini (which includes Old World monkeys, New World monkeys, and apes) manifested a higher median $\theta_{\text {evo }}$ value than Strepsirrhini (encompassing lemurs, lorises, and galagos) (Figure 4a), a result supported by examining the $90 \%$ confidence limits of the median (Figures $4 \mathrm{~b}$ ). At the level of infraorder, Simiiformes (Old World monkeys, New World monkeys, and apes) exhibited a substantially higher median $\theta_{\text {evo }}$ value than other groups (Figure $4 \mathrm{a}$ ), and this finding was also supported by examination of $90 \%$ confidence intervals (Figure $4 \mathrm{~b}$ ). When considering subfamilies, Cercopithecinae (encompassing most Old World monkeys, including baboons, macaques, and vervet monkeys) provided the clearest evidence for abundant and likely efficacious

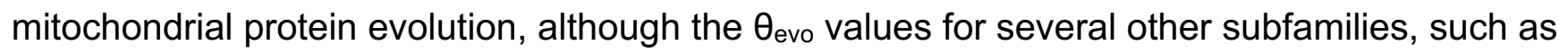
Cebinae (New World capuchin monkeys) and Colobinae (multiple genera of Old World monkeys) were also elevated (Figures 4c and 4d). Finally, when genera were analyzed, substantive mitochondrial protein change was clearly evident within Macaca (macaques) (Figures $4 \mathrm{e}$ and $4 \mathrm{f}$ ). Median $\theta_{\text {evo }}$ values were also elevated for the genera Chlorocebus (encompassing vervet and green monkeys), Gorilla (gorillas), Papio (baboons), and Trachypithecus (lutungs). 
We hoped to better understand the potential outcome of the bulk of specific primate substitutions, defined as a given ancestral character linked to a given descendent character along the same edge, occurring at the most highly conserved protein positions. Toward this goal, we located matches for specific substitutions from selected groups at different TSS cutoff values across mammalian orders. Intriguingly, as the TSS cut-off was decreased toward a value of five or lower, an enrichment of analyzed primate substitutions within specific clades became clear. Specifically, the five orders Hyracoidea (hyraxes), Proboscidea, Microbiotheria (the monito del monte), Monotremata (includes platypuses and spiny anteaters), and Pilosa were most enriched with primate substitutions of TSS less than or equal to five when compared to their share of substitutions at all TSSs (Figure 5a). When focusing upon substitutions at highly conserved sites found within haplorhines (Figure 5b) and simians (Figure 5c), the results were similar, with Diprotodontia (which includes multiple marsupial families) replacing Proboscidea within the five top-ranked orders.

The analyses described above report upon the trends detected across selected taxonomic levels. Since simians, as well as multiple descendent lineages, seem to be replete with substitutions at positions highly conserved across mammals, we looked closely at the substitutions inferred along the most ancestral simian tree edges at amino acid positions of TSS five or below, since the identification of those ancestral mutations may be informative regarding the lifestyle of early anthropoids and may allow speculation regarding the effects of later substitutions found among descendants. When focusing upon the branch leading to Old World monkeys, apes, and New World monkeys (edge i, Figure 6), a number of changes to highly conserved positions with a TSS of five or less were predicted. Intriguingly, all of these mutations were found within Complex IV, consistent with previous analyses highlighting substantial change to primate cytochrome $c$ oxidase components (Gissi et al. 2000; Grossman et al. 2004; Pierron et al. 2011, 2012). Additional changes likely to be functionally relevant, mostly located within Complex IV, were found along the descendent edges leading toward Old World monkeys and apes (edge ii, Figure 6), or toward New World monkeys (edge iii, Figure $6)$.

We then sought mutations outside of primates that would precisely match those with a TSS of five or less that are inferred at these three ancestral simian edges. Along the edge leading to Old World monkeys, apes, and New World monkeys (edge i, Figure 6), a Q52H change in Antilope cervicapra (blackbuck), which has a very high running speed, was predicted (Table 1). However, when considering the descendent edges leading to Old World monkeys and apes (edge ii, Figure 6) or to New World monkeys (edge iii, Figure 6), most of the substitutions at highly conserved sites matched those found within, or in edges leading to, groups quite conspicuous for their reduced metabolism, such as tuco-tucos, koalas, naked mole-rats, three-toed sloths, vampire bats, anteaters, and the monito del monte (Table 1). 


\section{Discussion:}

225

We mapped predicted amino acid substitutions to the edges of a tree inferred from the coding regions of mammalian mitochondrial genomes. Using this substitution map, we calculated the TSS, a measure of conservation robust against sampling biases and benefitting from a high dynamic range, at positions within mitochondria-encoded proteins. Using those TSSs, our substitution map, and branch lengths determined from protein coding mtDNA sequences, we calculated a score $\left(\theta_{\text {evo }}\right)$ that reports upon whether an unusual amount of functional change may have occurred along a phylogenetic tree edge. Specific substitutions along high-ranking tree edges that may be most impactful, based upon their location at conserved positions, are easily retrieved for further analysis. To our knowledge, we have carried out the most comprehensive analysis of mammalian mtDNA-encoded proteins ever performed, and our findings serve as a resource for those investigating the structure and function of mitochondria-encoded OXPHOS components. In addition, our dataset is highly valuable for those interested in selective forces that may have helped shape mtDNAs during the establishment and expansion of diverse mammalian clades.

Other approaches have previously been deployed toward the detection of substitutions linked to functional change within mitochondrial proteins (Garvin et al. 2015). For example, the $\mathrm{dN} / \mathrm{dS}$ ratio, where the number of non-synonymous nucleotide changes at non-synonymous sites is compared to the number of synonymous changes at synonymous sites, serves as the basis for several popular methods seeking unusually rapid evolution of proteins (Suzuki and Gojobori 1999; Yang et al. 2000; Kosakovsky Pond and Frost 2005). However, analysis of large datasets by this approach can be computationally intensive (Jeffares et al. 2015), and the ability of this metric to detect positive or relaxed selection on a protein may be diminished when many sites are highly conserved (Sharp 1997; Hughes 2007; Echave et al. 2016). Other weaknesses further limit the utility of dN/dS-based approaches (Kryazhimskiy and Plotkin 2008; Venkat et al. 2018; Wisotsky et al. 2020), including a difficulty in identifying instances of fixed adaptive substitutions subject to stabilizing selection, even though these changes are often linked to habitation of a new niche or to an interesting evolutionary transition (Hansen 1997; Bloom 2017). Alternative methodologies can take advantage of the chemical properties of amino acids to identify adaptive change in polypeptides (Woolley et al. 2003; McClellan et al. 2005). However, generalized measures of amino acid side behavior may not always allow detection of functional change, since the site-specific acceptability of a given substitution is ultimately decided within the context of its local protein environment (Zuckerkandl and Pauling 1965). Our rapid and computationally inexpensive approach will complement these existing and established methods that seek notable change to mitochondrial polypeptides, and we certainly anticipate the application of our method outside of the study of bioenergetics.

Orders and families can encompass members encountering a wide scope of ecological factors and characterized by widely divergent life histories, and we indeed encounter many outliers when examining the $\theta_{\text {evo }}$ values found within each taxonomic group. However, as might be expected based on generations of selection for survival within differing ecological 
267 niches, metabolic characteristics differ among taxonomic groups (McNab 2008; Griebeler and 268 Werner 2016), and we have noted a tendency for athleticism and high metabolic performance 269 to correspond with the conservation of mtDNA-encoded OXPHOS complex members among 270 land mammals. Indeed, artiodactyls and lagomorphs exhibit the greatest residual basal 271 metabolic rates among mammals, consistent with their often exceptional running speeds 272 (Hayssen and Lacy 1985; Lovegrove 1996, 2000; Garland 2009), and we detect the strongest conservation of mtDNA-encoded proteins among these orders. Similarly, horses can exhibit an exceptionally high mass-specific maximal rate of oxygen consumption (Hoppeler et al. 1987; Poole and Erickson 2011), and we also encounter strong conservation of mitochondrial proteins within this group. In contrast, many changes rapidly accumulate at conserved mitochondrial protein positions when considering tree edges assigned to the order Pilosa and family Bradypodidae. Accordingly, sloths are also characterized by very low metabolic rates, poor thermoregulation, and low levels of activity (Britton and Atkinson 1938; Pauli et al. 2016; Cliffe et al. 2018). Substantial change to positions conserved among mammals is also detected across primates, and we discuss the evolution of primate mitochondrial proteins below. Cladistic differences in the substitution profiles of mitochondrial proteins support the idea that metabolism can be subject to phylogenetic inertia that may limit adaptation to new diets and climes (Westoby et al. 1995; Hansen 1997).

\section{Primates are enriched for mutations likely to affect oxidative phosphorylation}

Consistent with the results described above, previous studies of primates, necessarily more limited in scale due to contemporary limitations in sequence availability, have also revealed accelerated evolution and unusual substitutions within mtDNA- and nucleus-encoded OXPHOS complex subunits (Gissi et al. 2000; Grossman et al. 2004; Pierron et al. 2011, 2012). At lower taxonomic levels, we found the clearest evidence of accelerated change of mtDNA-encoded proteins within the suborder Haplorrhini, the infraorder Simiiformes, and several families, subfamilies, and genera spread distributed throughout the primate tree. When those specific substitutions located at the most conserved positions across primates, haplorhines, or simian tree edges were sought outside of these groups, there was a substantial enrichment within the orders Hyracoidea, Proboscidea, Microbiotheria, Monotremata, Pilosa, and Diprotodontia. Low metabolism and difficulties in thermoregulation appear to typify the order Hyracoidea (Rübsamen et al. 1982). The related order, Proboscidea, includes elephants and their close relatives, which are also characterized by a reduced mass-specific basal and field metabolism relative to other mammals (Christiansen 2004). The order Microbiotheria contains one extant marsupial species, the monito del monte, which presents a low massspecific metabolic rate and can enter a prolonged torpor state in order to conserve energy (Bozinovic et al. 2004). The metabolic rate of monotremes is considerably lower than most placental mammals (Nicol 2017), with monotremes displaying the lowest body temperature among groups of mammals (Clarke and O'Connor 2014). The enfeebled metabolism of Pilosa members has been described above, and several members of the marsupial order Diprotodontia, such as the koala bear (Degabriele and Dawson 1979; Nagy and Martin 1985) 
309 and the wombat (Barboza et al. 1993; Evans et al. 2003), are low-activity mammals exhibiting reduced metabolism.

Next, we looked specifically at mutations occuring along three selected edges representing the origin of simians. The majority of those mutations at the most conserved positions were found in Complex IV, and a subset of these were previously placed at the interaction surface between cytochrome $c$ and cytochrome $c$ oxidase (Schmidt et al. 2005). Complex IV is a key control point for OXPHOS activity (Piccoli et al. 2006; Dalmonte et al. 2009; Arnold 2012; Hill 2016), and given the dearth of these selected mutations among other clades, compensation allowing functional neutrality (Starr and Thornton 2016) would, in our view, be highly unlikely. Instead, alteration of Complex IV activity by these substitutions is a more plausible scenario. For example, a change similar to the ancestral simian substitution COII D119N, where a negatively charged side chain is replaced by a neutral side chain, reduces cytochrome $c$ oxidase activity in the alpha-proteobacterium Rhodobacter sphaeroides (Wang et al. 1999; Zhen et al. 1999), and there is no clear evidence that this change might be compensated in the apposed cytochrome $c$ protein (Schmidt et al. 2005). At COI, D50N (ancestral to Old World monkeys and apes) and G49E (ancestral to New World monkeys) substitutions are found near residue D51, which is subject to redox-dependent conformational and protonation changes (Yoshikawa et al. 1998; Okuno et al. 2003; Maréchal et al. 2012; Sharma et al. 2017) and forms a key component of the 'H-channel' that serves as either a proton transfer pathway or as a dielectric well (Yoshikawa et al. 1998; Rich and Maréchal 2013; Sharma et al. 2017). The Q52H (ancestral to simians) substitution adds a titratable histidine to a region important for proton and water release (Son et al. 2017; Cai et al. 2018). All three of these COI substitutions, quite unusual among mammals, should be expected to alter enzyme kinetics.

\section{Primates substitutions are likely to compromise OXPHOS}

If those mutations in stem simians do lead to changes in OXPHOS activity, might they boost or reduce cellular metabolism? Equivalent substitutions to those found along these three edges, in findings that mirror those obtained by our analysis of all primate, haplorhine, or simian edges, were found among clades dominated by species with poor temperature regulation and/or low metabolic rates (Britton and Atkinson 1938; McNab 1966, 2003, 2009, 2012; Degabriele and Dawson 1979; Nagy and Martin 1985; Busch 1989; Christiansen 2004; Bozinovic et al. 2004; Stahl et al. 2012; Pauli et al. 2016; Cliffe et al. 2018). Specifically, inferred substitutions found along the tree edge leading to Old World monkeys could be matched in Myrmecophagidae (anteaters), Dromiciops (monito del montes), Bradypus (threetoed sloths), and Elephas (elephants). Inferred mutations found along the tree edge leading to New World monkeys were found in Desmodontinae (vampire bats), Bathyergidae (mole rats), Phascolarctos (koalas), and Ctenomys (tuco-tucos).

Taken together, our analysis of mammalian mtDNAs suggests a general reduction in the activity of OXPHOS complexes encoded by ancestral, and many extant, simians. These 
findings are consilient with recent data demonstrating that the energy expenditure of primates falls significantly below what would be anticipated when considering similarly sized mammals (Pontzer et al. 2014; Pontzer 2015) and with the extremely slow life history of many primates (Charnov 1993; Charnov and Berrigan 1993). In contrast, evidence that the changes to mtDNA-encoded proteins in primates would generally lead an increase in OXPHOS activity is scant, although it is certainly possible that mtDNA changes in select lineages, including reversions of substitutions that limit metabolic activity, may bypass the effects of ancestral OXPHOS component degradation.

If the mtDNA-encoded proteins of primates have indeed been adapted to a frugal lifestyle, poor diet, and reduced cellular metabolism, how might the expansion of an energetically expensive primate brain (Mink et al. 1981; Harris et al. 2012) be rationalized? The mass-specific metabolic rates of whole organisms cannot easily be directly linked to encephalization (Roth and Dicke 2005), or the extent to which the brain size corresponds to expectations based upon size (Jerison 2012). As an example, monotreme encephalization generally appears to fall in line with that of placental mammals (Macrini et al. 2006; Ashwell and Ashwell 2013; Nicol 2017), in spite of their comparatively reduced metabolism. Elephants also exhibit lower-than-expected metabolic rates (Christiansen 2004), yet elephants are more highly encephalized than many mammals (Hofman 1982; Roth and Dicke 2005). Lagomorphs, which exhibit a relatively high mass-specific metabolic rate (Hayssen and Lacy 1985; Lovegrove 2000) tend not to be highly encephalized (Kruska 2005; Roth and Dicke 2005), and artiodactyls are typically less encephalized than primates, although artiodactyls tend to exhibit an elevated mass-specific metabolic rate (Lovegrove 2000; Snodgrass et al. 2007; Pontzer et al. 2014; Pontzer 2015). If high metabolic performance is not directly linked to brain expansion, then one may speculate instead (Pontzer 2015), consistent with the expensive tissue hypothesis (Aiello and Wheeler 1995; Aiello et al. 2001), that OXPHOS components, and a cellular physiology selected for energetic parsimony, can reduce the basic metabolic requirements of mammals and license later evolution of a larger brain upon a sustained improvement in diet. Further support for this idea will require additional comparison of the mitochondrial activities and the metabolic properties of primates with those of other groups of mammals. 


\section{Methods:}

\section{Sequence acquisition and concatenation}

Record accessions for mammalian reference mtDNAs were obtained using the Organelle Genome Resources provided by the National Center for Biotechnology Information Reference Sequence project (NCBI RefSeq, Release 204, https://www.ncbi.nlm.nih.gov/genome/organelle/) (O'Leary et al. 2016). All records not containing ' $\mathrm{NC}$ - at the beginning of their accession name were removed, then the accession for the reptile Anolis punctatus was added. Using this list of accessions, full GenBank records for these mtDNAs were downloaded by use of the NCBI Batch Entrez server (https://www.ncbi.nlm.nih.gov/sites/batchentrez). This file (Supplemental File 4) was used as input for the 'vert_mtDNA_genbank_grab.py' script (https://github.com/corydunnlab/mammal_mitoprot_evolve).

\section{Sequence alignment}

The amino acid sequences of individual mitochondrial proteins extracted from the GenBank input file, as well as a concatenate of protein coding sequences, was aligned using the FFTNS-2 method in MAFFT v7.475 (Katoh and Standley 2013).

\section{Phylogenetic tree inference}

Our alignment of mtDNA sequences encoding mitochondrial proteins was used as input for RAxML-NG v0.9.0 (Kozlov et al. 2019) under a single partition, a GTR+FO+G4m model of DNA change, and a seed set as 200. 10 random and 10 parsimony-based starting trees were used to initiate tree inference, and the average relative Robinson-Foulds distance (Robinson and Foulds 1981) for the resulting set of trees was 0.01 . The best scoring tree is provided as Supplemental File 5. 600 bootstrap replicates were generated using RAxML-NG, and a weighted Robinson-Foulds distance converged below the 1\% cutoff value. Both Felsenstein's Bootstrap Proportions (Supplemental File 6) (Felsenstein 1985) and, perhaps more appropriate for our large dataset (Soltis and Soltis 2003), the Transfer Bootstrap Expectations (Supplemental File 7) (Lemoine et al. 2018) were calculated and used to label our best scoring tree. The best maximum likelihood tree was used for downstream analyses after using FigTree 1.4.4 (https://github.com/rambaut/figtree/releases) to place the root upon the branch leading to Anolis punctatus. 
423

424

425

426

427

428

429

430

431

432

433

434

435

436

437

438

439

440

441

442

443

444

\section{Calculation and classification of edge $\theta_{\text {evo }}$ values}

GenBank records, sequence alignments of mitochondrial proteins, and our best maximum likelihood tree were used as input for the script 'mtDNA_protein_evolution_calculator.py' (https://github.com/corydunnlab/mammal_mitoprot_evolve). Within this script, PAGAN v0.61(Löytynoja et al. 2012) is called to perform ancestral prediction of protein sequences at internal tree nodes, and the resulting PAGAN alignments were ungapped using the Bos taurus reference sequence (NC_006853.1). A PAGAN output tree is provided as Supplemental File 8. Taxonomy of input accessions was recovered from the NCBI Taxonomy Database (access date: January 29, 2021). Taxonomy of internal edges at a given taxonomic level was determined by unanimous agreement among descendent edges. If multiple taxons were found downstream of a descendent edge, 'MIXED' was assigned to that edge at that taxonomic level. Edge $\theta_{\text {evo }}$ values were further examined and plotted in GraphPad Prism v9.0.2, and only taxonomic groups containing five or more edges (allowing calculation of confidence intervals of greater than or equal to $90 \%$ ) are reported in our median-based analyses of specific taxonomic groups.

Enrichment of specific substitutions from a chosen clade within other clades, assessed at different levels of conservation

Specific substitutions found within the order Primates, the suborder Haplorrhini, and the infraorder Simiiformes were extracted from our table (Supplemental File 1) containing all amino acid substitutions at analyzed positions and their associated taxonomic assignments. These same substitutions were then sought among edges found outside of these selected groups.

The recovered dataset was filtered by TSS to determine the enrichment of simian substitutions in other clades at different levels of conservation. These analysis were performed using the scripts 'primates_specific_substitutions_outside_of_primates_with_TSS_enrichment.py', 'haplorrhini_specific_substitutions_outside_of_haplorrhini_with_TSS_enrichment.py', and 'simiiformes_specific_substitutions_outside_of_simiiformes_with_TSS_enrichment.py' (https://github.com/corydunnlab/mammal_mitoprot_evolve).

Detection of specific substitutions found along a selected edge across the phylogenetic tree

Provided a table containing all amino acid substitutions at analyzed positions and their associated taxonomic data (Supplemental File 1), a selected edge, and a TSS threshold, the script 'TSS_five_or_below_inside_and_outside_selected_edge.py' (https://github.com/corydunnlab/mammal_mitoprot_evolve) finds substitutions along the selected edge at alignment positions below the provided TSS value, as well as those specific substitutions located in any other edge besides the selected edge. 


\section{Author contributions:}

C.D.D. conceived of the methodology. C.D.D. and B.A.A. wrote software. C.D.D. and V.S. analyzed data. B.A.A., V.S., and C.D.D. wrote the manuscript.

\section{Acknowledgements:}

Funding for this project was obtained from the Sigrid Jusélius Foundation (Senior Researcher and Project Grants to C.D.D and V.S.), the European Research Council (ERC Starting Grant RevMito 637649 to C.D.D.), the Academy of Finland (to C.D.D. and V.S.), the University of Helsinki (to V.S.) and the Magnus Ehrnrooth Foundation (to V.S). C.D.D. and V.S. also thank the Center for Scientific Computing, Finland (Puhti and Mahti supercomputers), the Information Technology for Science Group, University of Helsinki (Ukko2 cluster) and PRACE (Marconi100 hosted at CINECA, Italy) for essential computational support. We thank Gülayşe İnce Dunn, Svetlana Konovalova, and Tamara Somborac for comments on the manuscript.

\section{References:}

Aiello L. C., and P. Wheeler, 1995 The Expensive-Tissue Hypothesis: The Brain and the Digestive System in Human and Primate Evolution. Current Anthropology 36: 199-221.

Aiello L. C., N. Bates, and T. Joffe, 2001 In defense of the Expensive Tissue Hypothesis, pp. 57-78 in Evolutionary Anatomy of the Primate Cerebral Cortex, edited by Falk D., Gibson K. R. Cambridge University Press, Cambridge.

Arnold S., 2012 The power of life-Cytochrome c oxidase takes center stage in metabolic control, cell signalling and survival. Mitochondrion 12: 46-56.

Ashwell K. W. S., and K. Ashwell, 2013 Cerebral cortex and claustrum/endopiriform complex. Neurobiology of Monotremes: Brain Evolution in Our Distant Mammalian Cousins, ed KWS Ashwell (Collingwood, Vic: CSIRO Publishing) 131-160.

Barboza P. S., I. D. Hume, and J. V. Nolan, 1993 Nitrogen Metabolism and Requirements of Nitrogen and Energy in the Wombats (Marsupialia: Vombatidae). Physiol. Zool. 66: 807828.

Bloom J. D., 2017 Identification of positive selection in genes is greatly improved by using experimentally informed site-specific models. Biol. Direct 12: 1.

Bonen L., R. S. Cunningham, M. W. Gray, and W. F. Doolittle, 1977 Wheat embryo mitochondrial $18 S$ ribosomal RNA: evidence for its prokaryotic nature. Nucleic Acids Res. 4: 663-671.

Bortoluzzi C., M. Bosse, M. F. L. Derks, R. P. M. A. Crooijmans, M. A. M. Groenen, et al., 2020 The type of bottleneck matters: Insights into the deleterious variation landscape of small 
managed populations. Evol. Appl. 13: 330-341.

502

503

504

505

506

507

508

509

510

511

512

513

514

515

516

517

518

519

520

521

522

523

524

525

526

527

528

529

530

531

532

Bozinovic F., G. Ruiz, and M. Rosenmann, 2004 Energetics and torpor of a South American "living fossil", the microbiotheriid Dromiciops gliroides. J. Comp. Physiol. B 174: 293-297.

Britton S. W., and W. E. Atkinson, 1938 Poikilothermism in the Sloth. J. Mammal. 19: 94-99.

Busch C., 1989 Metabolic rate and thermoregulation in two species of tuco-tuco, Ctenomys talarum and Ctenomys australis (Caviomorpha, Octodontidae). Comp. Biochem. Physiol. A Comp. Physiol. 93: 345-347.

Cai X., K. Haider, J. Lu, S. Radic, C. Y. Son, et al., 2018 Network analysis of a proposed exit pathway for protons to the P-side of cytochrome $\mathrm{c}$ oxidase. Biochim. Biophys. Acta Bioenerg. 1859: 997-1005.

Castoe T. A., Z. J. Jiang, W. Gu, Z. O. Wang, and D. D. Pollock, 2008 Adaptive evolution and functional redesign of core metabolic proteins in snakes. PLoS One 3: e2201.

Charnov E. L., 1993 Life History Invariants: Some Explorations of Symmetry in Evolutionary Ecology. Oxford University Press.

Charnov E. L., and D. Berrigan, 1993 Why do female primates have such long lifespans and so few babies? Or life in the slow lane. Evolutionary Anthropology: Issues, News, and Reviews 1: 191-194.

Christiansen P., 2004 Body size in proboscideans, with notes on elephant metabolism. Zool. J. Linn. Soc. 140: 523-549.

Christie J. R., and M. Beekman, 2017 Uniparental Inheritance Promotes Adaptive Evolution in Cytoplasmic Genomes. Mol. Biol. Evol. 34: 677-691.

Clarke A., and M. I. O'Connor, 2014 Diet and body temperature in mammals and birds: Diet and body temperature. Glob. Ecol. Biogeogr. 23: 1000-1008.

Cliffe R. N., D. M. Scantlebury, S. J. Kennedy, J. Avey-Arroyo, D. Mindich, et al., 2018 The metabolic response of the Bradypus sloth to temperature. PeerJ 6: e5600.

Dalmonte M. E., E. Forte, M. L. Genova, A. Giuffrè, P. Sarti, et al., 2009 Control of Respiration by Cytochrome c Oxidase in Intact Cells. J. Biol. Chem. 284: 32331-32335.

Dalziel A. C., C. D. Moyes, E. Fredriksson, and S. C. Lougheed, 2006 Molecular evolution of cytochrome c oxidase in high-performance fish (teleostei: Scombroidei). J. Mol. Evol. 62: 319-331.

Degabriele R., and T. J. Dawson, 1979 Metabolism and heat balance in an arboreal marsupial, the koala (Phascolarctos cinereus). J. Comp. Physiol. 134: 293-301. 
533 Dunn C. D., B. A. Akpınar, and V. Sharma, 2020 An Unusual Amino Acid Substitution Within

534

535

536

537

538

539

540

541

542

543

544

545

546

547

548

549

550

551

552

553

554

555

556

557

558

559

560

561

562

563

564 Hummingbird Cytochrome c Oxidase Alters a Key Proton-Conducting Channel. G3 10: 2477-2485.

Echave J., S. J. Spielman, and C. O. Wilke, 2016 Causes of evolutionary rate variation among protein sites. Nat. Rev. Genet. 17: 109-121.

Evans M., B. Green, and K. Newgrain, 2003 The field energetics and water fluxes of free-living wombats (Marsupialia: Vombatidae). Oecologia 137: 171-180.

Felsenstein J., 1985 CONFIDENCE LIMITS ON PHYLOGENIES: AN APPROACH USING THE BOOTSTRAP. Evolution 39: 783-791.

Fonseca R. R. da, W. E. Johnson, S. J. O'Brien, M. J. Ramos, and A. Antunes, 2008 The adaptive evolution of the mammalian mitochondrial genome. BMC Genomics 9: 119.

Garland T., 2009 The relation between maximal running speed and body mass in terrestrial mammals. J. Zool. 199: 157-170.

Garvin M. R., J. P. Bielawski, L. A. Sazanov, and A. J. Gharrett, 2015 Review and metaanalysis of natural selection in mitochondrial complex I in metazoans. J. Zoolog. Syst. Evol. Res. 53: 1-17.

Geiser F., 1994 Hibernation and Daily Torpor in Marsupials - a Review. Aust. J. Zool. 42: 1-16.

Gissi C., A. Reyes, G. Pesole, and C. Saccone, 2000 Lineage-specific evolutionary rate in mammalian mtDNA. Mol. Biol. Evol. 17: 1022-1031.

Griebeler E. M., and J. Werner, 2016 Mass, phylogeny, and temperature are sufficient to explain differences in metabolic scaling across mammalian orders? Ecol. Evol. 6: 83528365.

Grossman L. I., D. E. Wildman, T. R. Schmidt, and M. Goodman, 2004 Accelerated evolution of the electron transport chain in anthropoid primates. Trends Genet. 20: 578-585.

Gustafsson C. M., M. Falkenberg, and N.-G. Larsson, 2016 Maintenance and Expression of Mammalian Mitochondrial DNA. Annu. Rev. Biochem. 85: 133-160.

Hansen T. F., 1997 STABILIZING SELECTION AND THE COMPARATIVE ANALYSIS OF ADAPTATION. Evolution 51: 1341-1351.

Harris J. J., R. Jolivet, and D. Attwell, 2012 Synaptic energy use and supply. Neuron 75: 762 777.

Hayssen V., and R. C. Lacy, 1985 Basal metabolic rates in mammals: taxonomic differences in the allometry of BMR and body mass. Comp. Biochem. Physiol. A Comp. Physiol. 81: 


$$
741-754 .
$$

566

567

568

569

570

571

572

573

574

575

576

577

578

579

580

581

582

583

584

585

586

587

588

589

590

591

592

593

594

595

Hill G. E., 2016 Mitonuclear coevolution as the genesis of speciation and the mitochondrial DNA barcode gap. Ecol. Evol. 6: 5831-5842.

Hirakawa H., and Y. Nagasaka, 2018 Evidence for Ussurian tube-nosed bats (Murina ussuriensis) hibernating in snow. Sci. Rep. 8: 12047.

Hoekstra R. F., 2000 Evolutionary origin and consequences of uniparental mitochondrial inheritance. Hum. Reprod. 15 Suppl 2: 102-111.

Hofman M. A., 1982 Encephalization in mammals in relation to the size of the cerebral cortex. Brain Behav. Evol. 20: 84-96.

Hoppeler H., J. H. Jones, S. L. Lindstedt, H. Claassen, K. E. Longworth, et al., 1987 Relating maximal oxygen consumption to skeletal muscle mitochondria in horses. Equine exercise physiology 2: 278-289.

Hughes A. L., 2007 Looking for Darwin in all the wrong places: the misguided quest for positive selection at the nucleotide sequence level. Heredity 99: 364-373.

IUCN, 2008a Panthera tigris ssp. amoyensis: Nyhus, P: The IUCN Red List of Threatened Species 2008: e.T15965A5334628. IUCN Red List of Threatened Species.

IUCN, 2008b Budorcas taxicolor: Song, Y.-L., Smith, A.T. \& MacKinnon, J: The IUCN Red List of Threatened Species 2008: e.T3160A9643719. IUCN Red List of Threatened Species.

IUCN, 2016a Ursus thibetanus: Garshelis, D. \& Steinmetz, R: The IUCN Red List of Threatened Species 2020: e.T22824A166528664. IUCN Red List of Threatened Species.

IUCN, 2016b Gorilla gorilla: Maisels, F., bergl, R.a. \& Williamson, E.a: The IUCN red list of threatened species 2018: E.T9404A136250858. IUCN Red List of Threatened Species.

Jeffares D. C., B. Tomiczek, V. Sojo, and M. dos Reis, 2015 A beginners guide to estimating the non-synonymous to synonymous rate ratio of all protein-coding genes in a genome. Methods Mol. Biol. 1201: 65-90.

Jerison H., 2012 Evolution of The Brain and Intelligence. Elsevier.

Katoh K., and D. M. Standley, 2013 MAFFT multiple sequence alignment software version 7: improvements in performance and usability. Mol. Biol. Evol. 30: 772-780.

Kosakovsky Pond S. L., and S. D. W. Frost, 2005 Not so different after all: a comparison of methods for detecting amino acid sites under selection. Mol. Biol. Evol. 22: 1208-1222.

Kozlov A. M., D. Darriba, T. Flouri, B. Morel, and A. Stamatakis, 2019 RAxML-NG: a fast, 
scalable and user-friendly tool for maximum likelihood phylogenetic inference. Bioinformatics 35: 4453-4455.

Kruska D. C. T., 2005 On the evolutionary significance of encephalization in some eutherian mammals: effects of adaptive radiation, domestication, and feralization. Brain Behav. Evol. 65: 73-108.

Kryazhimskiy S., and J. B. Plotkin, 2008 The population genetics of dN/dS. PLoS Genet. 4: e1000304.

Larson G., and D. Q. Fuller, 2014 The Evolution of Animal Domestication. Annu. Rev. Ecol. Evol. Syst. 45: 115-136.

Lemoine F., J.-B. Domelevo Entfellner, E. Wilkinson, D. Correia, M. Dávila Felipe, et al., 2018 Renewing Felsenstein's phylogenetic bootstrap in the era of big data. Nature 556: 452456.

Lovegrove B. G., 1996 The low basal metabolic rates of marsupials: the influence of torpor and zoogeography, pp. 141-151 in Adaptations to the Cold (F. Geiser, AJ Hulbert, and SC Nicol, Eds.). Tenth International Hibernation Symposium, University of New England Press, Armidale, Australia,.

Lovegrove B. G., 2000 The Zoogeography of Mammalian Basal Metabolic Rate. Am. Nat. 156: 201-219.

Lovegrove B. G., 2004 Locomotor mode, maximum running speed, and basal metabolic rate in placental mammals. Physiol. Biochem. Zool. 77: 916-928.

Löytynoja A., A. J. Vilella, and N. Goldman, 2012 Accurate extension of multiple sequence alignments using a phylogeny-aware graph algorithm. Bioinformatics 28: 1684-1691.

MacMillen R. E., and J. E. Nelson, 1969 Bioenergetics and body size in dasyruid marsupials. Am. J. Physiol. 217: 1246-1251.

Macrini T. E., T. Rowe, and M. Archer, 2006 Description of a cranial endocast from a fossil platypus, Obdurodon dicksoni (Monotremata, Ornithorhynchidae), and the relevance of endocranial characters to monotreme monophyly. J. Morphol. 267: 1000-1015.

Maréchal A., B. Meunier, and P. R. Rich, 2012 Assignment of the CO-sensitive carboxyl group in mitochondrial forms of cytochrome c oxidase using yeast mutants. Biochim. Biophys. Acta 1817: 1921-1924.

McClellan D. A., E. J. Palfreyman, M. J. Smith, J. L. Moss, R. G. Christensen, et al., 2005 Physicochemical evolution and molecular adaptation of the cetacean and artiodactyl cytochrome b proteins. Mol. Biol. Evol. 22: 437-455. 
629

McNab B. K., 1966 The metabolism of fossorial rodents: A study of convergence. Ecology 47: 712-733.

McNab B. K., 1992 The comparative energetics of rigid endothermy: the Arvicolidae. J. Zool. 227: 585-606.

McNab B. K., 2003 Standard energetics of phyllostomid bats: the inadequacies of phylogenetic-contrast analyses. Comp. Biochem. Physiol. A Mol. Integr. Physiol. 135: 357-368.

McNab B. K., 2008 An analysis of the factors that influence the level and scaling of mammalian BMR. Comp. Biochem. Physiol. A Mol. Integr. Physiol. 151: 5-28.

McNab B. K., 2009 Physiological convergence amongst ant-eating and termite-eating mammals. J. Zool. 203: 485-510.

McNab B. K., 2012 Extreme Measures: The Ecological Energetics of Birds and Mammals. University of Chicago Press.

Mink J. W., R. J. Blumenschine, and D. B. Adams, 1981 Ratio of central nervous system to body metabolism in vertebrates: its constancy and functional basis. Am. J. Physiol. 241: R203-12.

Nachman M. W., W. M. Brown, M. Stoneking, and C. F. Aquadro, 1996 Nonneutral mitochondrial DNA variation in humans and chimpanzees. Genetics 142: 953-963.

Nachman M. W., 1998 Deleterious mutations in animal mitochondrial DNA, pp. 61-69 in Mutation and Evolution, edited by Woodruff R. C., Thompson J. N. Springer Netherlands, Dordrecht.

Nagy K. A., and R. W. Martin, 1985 Field Metabolic Rate, Water Flux, Food Consumption and Time Budget of Koalas, Phascolarctos Cinereus (Marsupialia: Phascolarctidae) in Victoria. Aust. J. Zool. 33: 655-665.

Nicol S. C., 2017 Energy Homeostasis in Monotremes. Front. Neurosci. 11: 195.

Ohta T., 1973 Slightly deleterious mutant substitutions in evolution. Nature 246: 96-98.

Okuno D., T. Iwase, K. Shinzawa-Itoh, S. Yoshikawa, and T. Kitagawa, 2003 FTIR detection of protonation/deprotonation of key carboxyl side chains caused by redox change of the $\mathrm{Cu}(\mathrm{A})$-heme a moiety and ligand dissociation from the heme a3-Cu(B) center of bovine heart cytochrome c oxidase. J. Am. Chem. Soc. 125: 7209-7218.

O'Leary N. A., M. W. Wright, J. R. Brister, S. Ciufo, D. Haddad, et al., 2016 Reference sequence (RefSeq) database at NCBI: current status, taxonomic expansion, and functional annotation. Nucleic Acids Res. 44: D733-45. 
662

663

664

665

666

667

668

669

670

671

672

673

674

675

676

677

678

679

680

681

682

683

684

685

686

687

688

689

690

691

692

693

Park T. J., J. Reznick, B. L. Peterson, G. Blass, D. Omerbašić, et al., 2017 Fructose-driven glycolysis supports anoxia resistance in the naked mole-rat. Science 356: 307-311.

Pauli J. N., M. Z. Peery, E. D. Fountain, and W. H. Karasov, 2016 Arboreal Folivores Limit Their Energetic Output, All the Way to Slothfulness. Am. Nat. 188: 196-204.

Pfanner N., B. Warscheid, and N. Wiedemann, 2019 Mitochondrial proteins: from biogenesis to functional networks. Nat. Rev. Mol. Cell Biol. 20: 267-284.

Piccoli C., R. Scrima, D. Boffoli, and N. Capitanio, 2006 Control by cytochrome c oxidase of the cellular oxidative phosphorylation system depends on the mitochondrial energy state. Biochem. J 396: 573-583.

Pierron D., J. C. Opazo, M. Heiske, Z. Papper, M. Uddin, et al., 2011 Silencing, positive selection and parallel evolution: busy history of primate cytochromes C. PLoS One 6: e26269.

Pierron D., D. E. Wildman, M. Hüttemann, T. Letellier, and L. I. Grossman, 2012 Evolution of the couple cytochrome $\mathrm{c}$ and cytochrome $\mathrm{c}$ oxidase in primates. Adv. Exp. Med. Biol. 748: 185-213.

Pontzer H., D. A. Raichlen, A. D. Gordon, K. K. Schroepfer-Walker, B. Hare, et al., 2014 Primate energy expenditure and life history. Proc. Natl. Acad. Sci. U. S. A. 111: 14331437.

Pontzer H., 2015 Energy Expenditure in Humans and Other Primates: A New Synthesis. Annu. Rev. Anthropol. 44: 169-187.

Poole D. C., and H. H. Erickson, 2011 Highly athletic terrestrial mammals: horses and dogs. Compr. Physiol. 1: 1-37.

Rich P. R., and A. Maréchal, 2013 Functions of the hydrophilic channels in protonmotive cytochrome c oxidase. J. R. Soc. Interface 10: 20130183.

Robinson D. F., and L. R. Foulds, 1981 Comparison of phylogenetic trees. Math. Biosci. 53: 131-147.

Roger A. J., S. A. Muñoz-Gómez, and R. Kamikawa, 2017 The Origin and Diversification of Mitochondria. Curr. Biol. 27: R1177-R1192.

Roth G., and U. Dicke, 2005 Evolution of the brain and intelligence. Trends Cogn. Sci. 9: 250257.

Rübsamen K., I. D. Hume, and W. von Engelhardt, 1982 Physiology of the rock hyrax. Comp. Biochem. Physiol. A Comp. Physiol. 72: 271-277. 
694

695

696

697

698

699

700

701

702

703

704

705

706

707

708

709

710

711

712

713

714

715

716

717

718

719

720

721

722

723

724

725

726

Sato K., and M. Sato, 2017 Multiple ways to prevent transmission of paternal mitochondrial DNA for maternal inheritance in animals. J. Biochem. 162: 247-253.

Schmidt T. R., D. E. Wildman, M. Uddin, J. C. Opazo, M. Goodman, et al., 2005 Rapid electrostatic evolution at the binding site for cytochrome $\mathrm{c}$ on cytochrome $\mathrm{c}$ oxidase in anthropoid primates. Proc. Natl. Acad. Sci. U. S. A. 102: 6379-6384.

Schoch C. L., S. Ciufo, M. Domrachev, C. L. Hotton, S. Kannan, et al., 2020 NCBI Taxonomy: a comprehensive update on curation, resources and tools. Database 2020. https://doi.org/10.1093/database/baaa062

Sharma V., P. G. Jambrina, M. Kaukonen, E. Rosta, and P. R. Rich, 2017 Insights into functions of the $\mathrm{H}$ channel of cytochrome $\mathrm{c}$ oxidase from atomistic molecular dynamics simulations. Proc. Natl. Acad. Sci. U. S. A. 114: E10339-E10348.

Sharp P. M., 1997 In search of molecular darwinism. Nature 385: 111-112.

Shen Y.-Y., L. Liang, Z.-H. Zhu, W.-P. Zhou, D. M. Irwin, et al., 2010 Adaptive evolution of energy metabolism genes and the origin of flight in bats. Proc. Natl. Acad. Sci. U. S. A. 107: 8666-8671.

Snodgrass J. J., W. R. Leonard, and M. L. Robertson, 2007 Primate Bioenergetics: An Evolutionary Perspective, pp. 703-737 in PRIMATE ORIGINS: Adaptations and Evolution, edited by Ravosa M. J., Dagosto M. Springer US, Boston, MA.

Soltis P. S., and D. E. Soltis, 2003 Applying the Bootstrap in Phylogeny Reconstruction. Stat. Sci. 18: 256-267.

Son C. Y., A. Yethiraj, and Q. Cui, 2017 Cavity hydration dynamics in cytochrome c oxidase and functional implications. Proc. Natl. Acad. Sci. U. S. A. 114: E8830-E8836.

Sousa J. S., E. D'Imprima, and J. Vonck, 2018 Mitochondrial Respiratory Chain Complexes, pp. 167-227 in Membrane Protein Complexes: Structure and Function, edited by Harris J. R., Boekema E. J. Springer Singapore, Singapore.

Stahl M., C. Osmann, S. Ortmann, M. Kreuzer, J.-M. Hatt, et al., 2012 Energy intake for maintenance in a mammal with a low basal metabolism, the giant anteater (Myrmecophaga tridactyla). J. Anim. Physiol. Anim. Nutr. 96: 818-824.

Starr T. N., and J. W. Thornton, 2016 Epistasis in protein evolution. Protein Sci. 25: 12041218.

Stewart J. B., C. Freyer, J. L. Elson, A. Wredenberg, Z. Cansu, et al., 2008 Strong purifying selection in transmission of mammalian mitochondrial DNA. PLoS Biol. 6: e10.

Suzuki Y., and T. Gojobori, 1999 A method for detecting positive selection at single amino acid 
sites. Mol. Biol. Evol. 16: 1315-1328.

728

729

730

731

732

733

734

735

736

737

738

739

740

741

742

743

744

745

746

747

748

749

750

751
Venkat A., M. W. Hahn, and J. W. Thornton, 2018 Multinucleotide mutations cause false inferences of lineage-specific positive selection. Nat Ecol Evol 2: 1280-1288.

Wang K., Y. Zhen, R. Sadoski, S. Grinnell, L. Geren, et al., 1999 Definition of the interaction domain for cytochrome $\mathrm{c}$ on cytochrome c oxidase. li. Rapid kinetic analysis of electron transfer from cytochrome $c$ to Rhodobacter sphaeroides cytochrome oxidase surface mutants. J. Biol. Chem. 274: 38042-38050.

Westoby M., M. R. Leishman, and J. M. Lord, 1995 On Misinterpreting the 'Phylogenetic Correction'. J. Ecol. 83: 531.

Wisotsky S. R., S. L. Kosakovsky Pond, S. D. Shank, and S. V. Muse, 2020 Synonymous Siteto-Site Substitution Rate Variation Dramatically Inflates False Positive Rates of Selection Analyses: Ignore at Your Own Peril. Mol. Biol. Evol. 37: 2430-2439.

Woolley S., J. Johnson, M. J. Smith, K. A. Crandall, and D. A. McClellan, 2003 TreeSAAP: selection on amino acid properties using phylogenetic trees. Bioinformatics 19: 671-672.

Yang Z., R. Nielsen, N. Goldman, and A. M. Pedersen, 2000 Codon-substitution models for heterogeneous selection pressure at amino acid sites. Genetics 155: 431-449.

Yoshikawa S., K. Shinzawa-Itoh, R. Nakashima, R. Yaono, E. Yamashita, et al., 1998 Redoxcoupled crystal structural changes in bovine heart cytochrome c oxidase. Science 280: 1723-1729.

Zhen Y., C. W. Hoganson, G. T. Babcock, and S. Ferguson-Miller, 1999 Definition of the interaction domain for cytochrome c on cytochrome c oxidase. I. Biochemical, spectral, and kinetic characterization of surface mutants in subunit ii of Rhodobacter sphaeroides cytochrome aa(3). J. Biol. Chem. 274: 38032-38041.

Zuckerkandl E., and L. Pauling, 1965 Evolutionary Divergence and Convergence in Proteins. Evolving Genes and Proteins 97-166. 
bioRxiv preprint doi: https://doi.org/10.1101/2021.03.10.434614; this version posted March 11, 2021. The copyright holder for this preprint (which was not certified by peer review) is the author/funder. All rights reserved. No reuse allowed without permission.

\begin{tabular}{|c|c|c|c|c|c|}
\hline Edge analyzed & Edge description & Complex & Substitution & Matching edge & Comment on taxonomy \\
\hline $\mathbf{i}$ & Edge leading to Old World monkeys, apes, and New World monkeys & IV & $\operatorname{cox} 1 Q_{52 H}$ & to Antilope cervicapra & Antilope cervicapra has a very high maximal running speed (Lovegrove 2004). \\
\hline ii & Edge leading to Old World monkeys and apes & 1 & ND1 C301L & Myrmecophagidae internal edge & $\begin{array}{l}\text { Daughter edges lead to Tamandua tetradactyla, Tamandua mexicana, Myrmecophaga } \\
\text { tridactyla anteaters typically exhibit a reduced basal metabolic rate and body temperature } \\
\text { relative to other mammals (Stahl et al. 2012; McNab 2009). }\end{array}$ \\
\hline ii & Edge leading to Old World monkeys and apes & IV & $\operatorname{COX2~142L~}$ & Dasyuromorphia internal edge & $\begin{array}{l}\text { Daughter edges encompass a number of marsupial families. Marsupials typically have mass } \\
\text { specific metabolic rates that are lower than placental mammals. Several species descending } \\
\text { from this edge undergo torpor, low-metabolism, low-temperature, deceased-activity state. } \\
\text { (MacMillen and Nelson, 1969; Geiser 1994). }\end{array}$ \\
\hline ii & Edge leading to Old World monkeys and apes & IV & $\operatorname{cox} 2$ 142L & to Dromiciops gliroides & $\begin{array}{l}\text { Dromiciops gliroides is a marsupial with a basal metabolic rate below that predicted of a } \\
\text { placental mammal of similar size. This organism can enter a prolonged torpor state induced } \\
\text { by low ambient temperature and reduced food intake (Bozinovic et al. 2004). }\end{array}$ \\
\hline ii & Edge leading to Old World monkeys and apes & IV & $\operatorname{cox} 2$ 142L & to Murina ussuriensis & $\begin{array}{l}\text { Murina ussuriensis is the only bat known to hibernate in snowbanks, a location may } \\
\text { provide greater temperature stability during hibernation (Hirakawa and Nagasaka 2018). }\end{array}$ \\
\hline ii & Edge leading to Old World monkeys and apes & IV & $\operatorname{cox} 2 \mathrm{M} 45 \mathrm{~T}$ & Bradypus internal edge & $\begin{array}{l}\text { Members of the Bradypus genus manifest greatly reduced metabolic rates and low activity } \\
\text { relative to other mammals, and the body temperatures of these sloths can fluctuate wildy } \\
\text { (Cliffe et al. 2018; Pauli et al. 2016; Britton and Atkinson 1938). }\end{array}$ \\
\hline ii & Edge leading to Old World monkeys and apes & IV & COX2 M45T & to Elephas antiquus & $\begin{array}{l}\text { Elephas antiquus (or Palaeoloxodon antiquus) is an extinct elephant of greater size than } \\
\text { extant elephants. Larger mammals tend to have lower mass-specific metabolic rates than } \\
\text { smaller mammals, and elephants have a lower energy expenditure and basal metabolic rate } \\
\text { than its size would predict (McNab 2012; Christiansen 2004) } \\
\end{array}$ \\
\hline iii & Edge leading to New World monkeys & 1 & ND4 S80T & Desmodontinae internal edge & $\begin{array}{l}\text { Daughter edges lead to Diphylla ecaudata, Diaemus youngi, and Desmodus rotundus. } \\
\text { Vampire bats typically have lower mass-independent basal metabolic rates than other bats } \\
\text { (McNab 2003). }\end{array}$ \\
\hline iii & Edge leading to New World monkeys & 1 & ND5 S343A & Arvicolinae internal edge & $\begin{array}{l}\text { Many arvicolids manifest a high mass-independent basal metabolic rate and high body } \\
\text { temperature, consistent with a high rate of energy expenditure (McNab 1992). }\end{array}$ \\
\hline iii & Edge leading to New World monkeys & 1 & ND5 S343A & Bathyergidae internal edge & $\begin{array}{l}\text { Daughter edges lead to the fossorial rodents Heterocephalus glaber (naked mole-rat) and } \\
\text { Fukomys damarensis (Damaraland mole-rat). Heterocepha/us glaber has a very low mass- } \\
\text { independent metabolic rate, is a poor thermoregulator, and is highly tolerant of hypoxia } \\
\text { (McNab 1966; Park et al. 2017). }\end{array}$ \\
\hline iii & Edge leading to New World monkeys & IV & COX1 G49E & to Phascolarctos cinereus & $\begin{array}{l}\text { The mass-independent metabolic rate of koalas are only } \sim 74 \% \text { of expectations for } \\
\text { marsupials of its size, and koalas are not characterized by high activity (Degabriele and } \\
\text { Dawson 1979; Nagy and Martin 1985). }\end{array}$ \\
\hline iii & Edge leading to New World monkeys & IV & COX1 G49E & to Ctenomys leucodon & $\begin{array}{l}\text { Tuco-tucos are fossorial rodents. Typically, tuco-tucos have low mass-independent } \\
\text { metabolic rates (Busch 1989). }\end{array}$ \\
\hline
\end{tabular}

Table 1: Substitutions found outside of primates matching those in selected primate ancestral edges. Those substitutions matching mutations inferred at the ancestral edges (i), (ii), and (iii) shown in Figure 6 are listed, along with comments regarding the metabolic proficiency of the associated clade or species. 


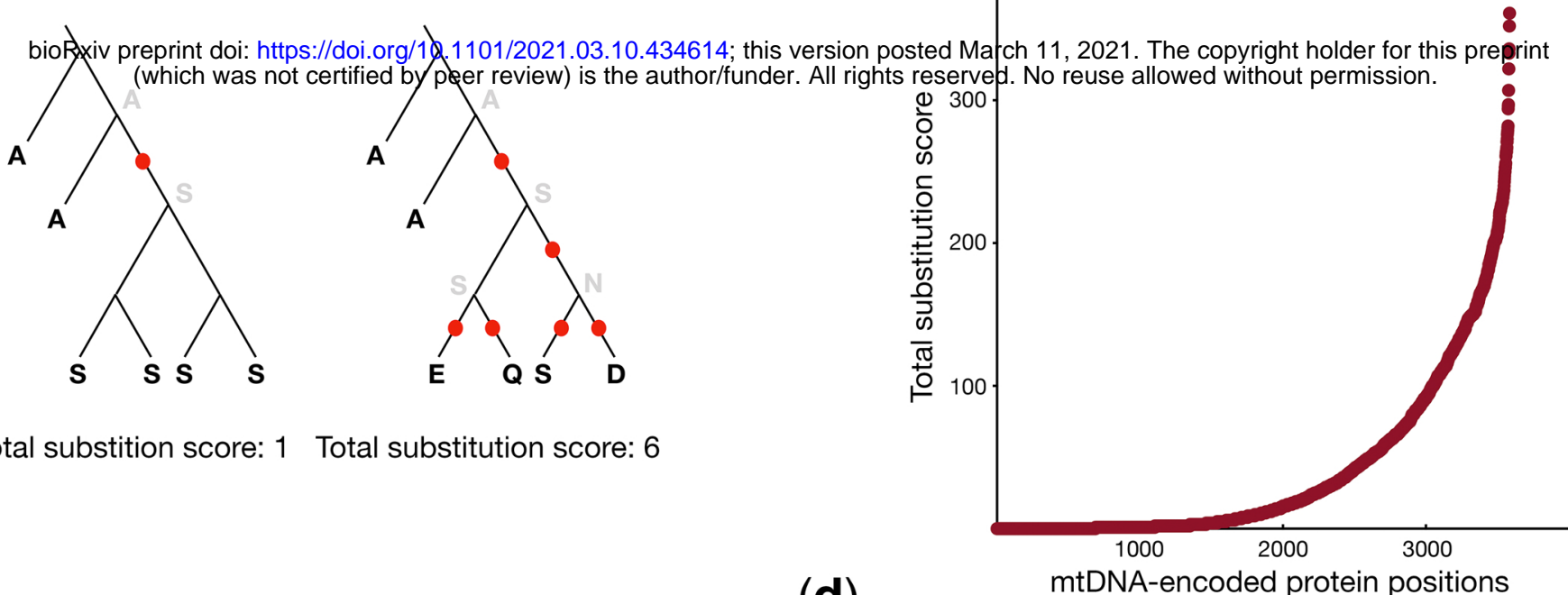

(c)

A substantive protein change sum (SPCS) is calculated by adding the $1 /(T S S+1)$ values of each substitution inferred along a tree edge

Linear regression is performed using the SPCS and nucleotide-based branch lengths (BLs) associated with each analyzed edge

The arctangent $\left(\theta_{\text {evo }}\right)$ of the regression residual divided by the $B L$ is calculated for each edge

(e)

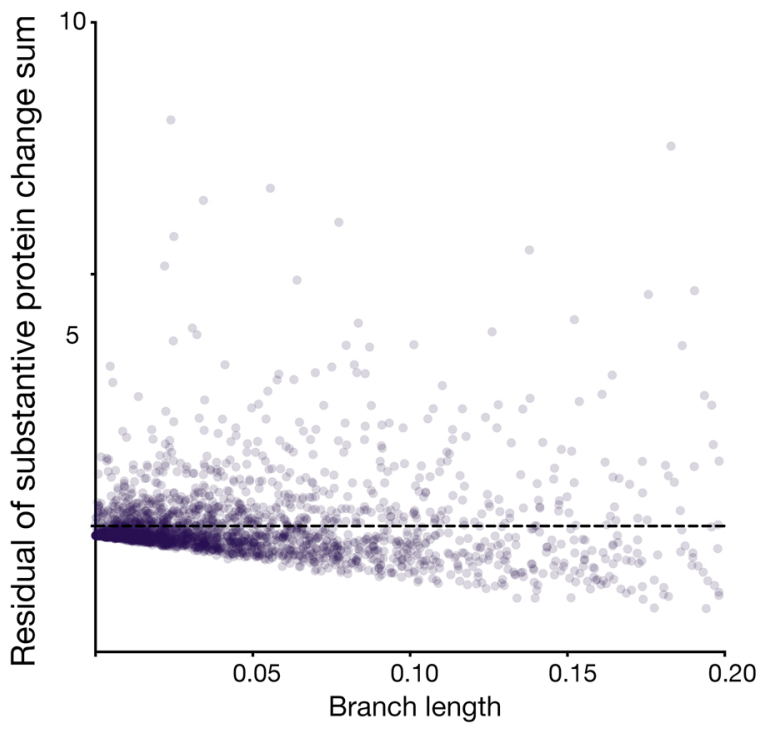

(d)

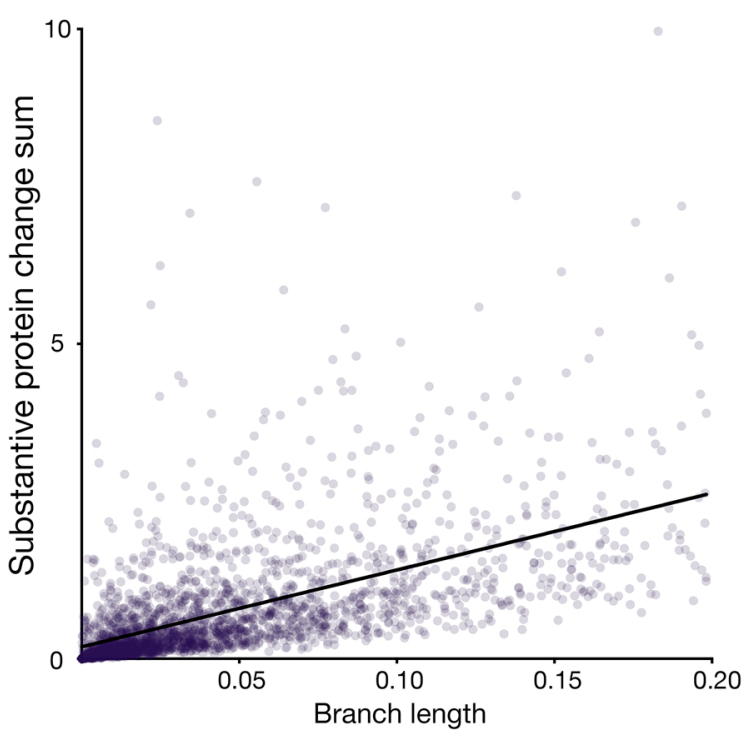

(f)

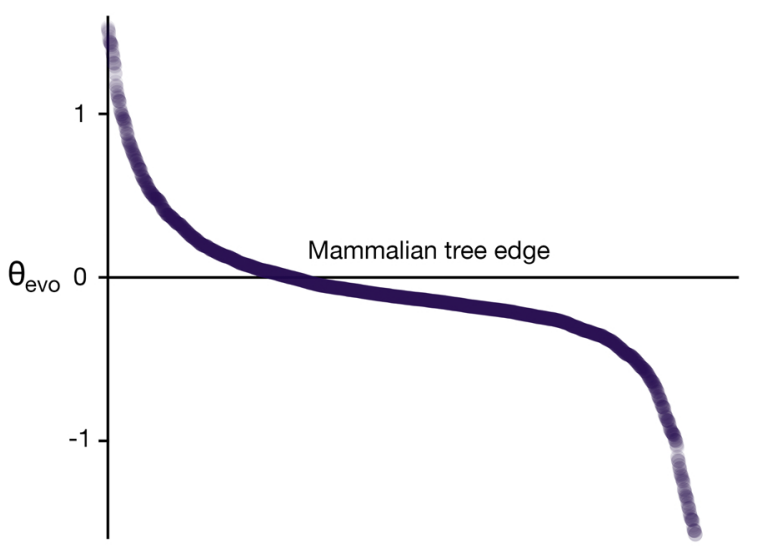

Figure 1: Detection of accelerated and potentially functional protein evolution along phylogenetic tree edges. (a) The total substitution score (TSS) is a measure of alignment position conservation. Character values at internal nodes are predicted, and inferred substitutions along an edge are summed. (b) The TSS values of all alignment positions gapped within less than $2 \%$ of inferred ancestral and input sequences are plotted for all mitochondria-encoded proteins. Alignment positions are ordered by increasing TSS value. (c) The methodology for detecting when an edge is characterized by greater-than-expected protein evolution is outlined: (d) The alignment position TSS for each substitution detected along an edge was added to 1, and the reciprocals of these values were summed to generate a substantive protein change sum (SPCS) for each edge found within a tree of mammalian mtDNA sequences. Edges with a branch length greater than or equal to 0.2 were removed, and linear regression was performed (black line). (e) Residuals for each sample were calculated, and (f) the arctangent of the residual divided by the branch length, $\theta_{\text {evo }}$, for each analyzed edge across all analyzed mitochondria-encoded amino acid positions is computed. 
bioRxiv preprint doi: https://doi.org/10.1101/2021.03.10.434614; this version posted March 11, 2021. The copyright holder for this preprint (which was not certified by peer review) is the author/funder. All rights reserved. No reuse allowed without permission.

(a)

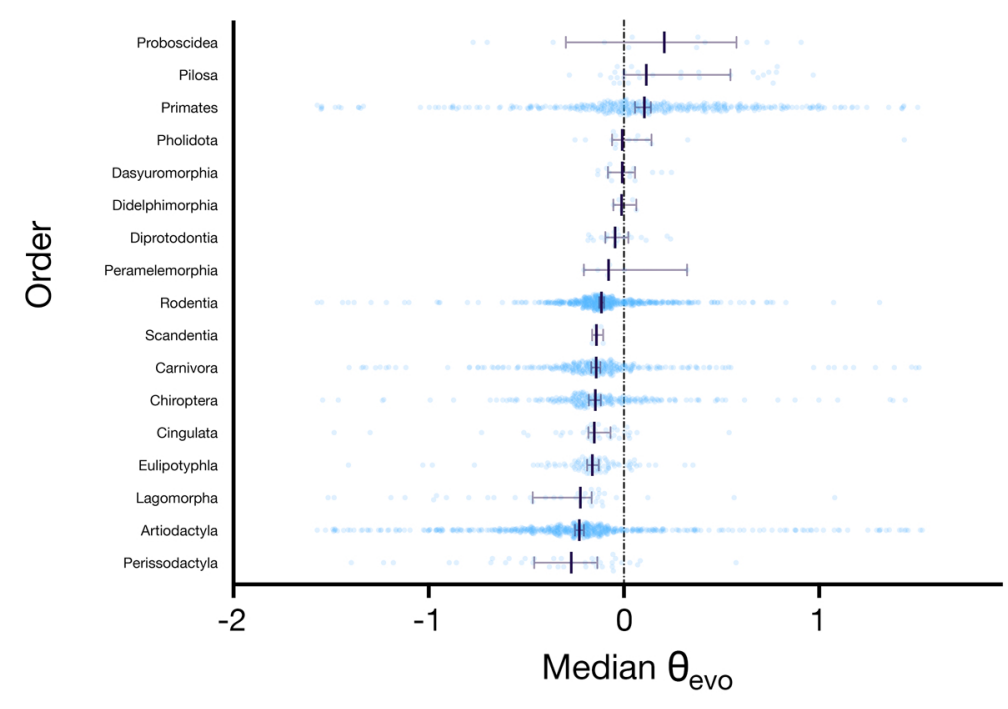

(b)

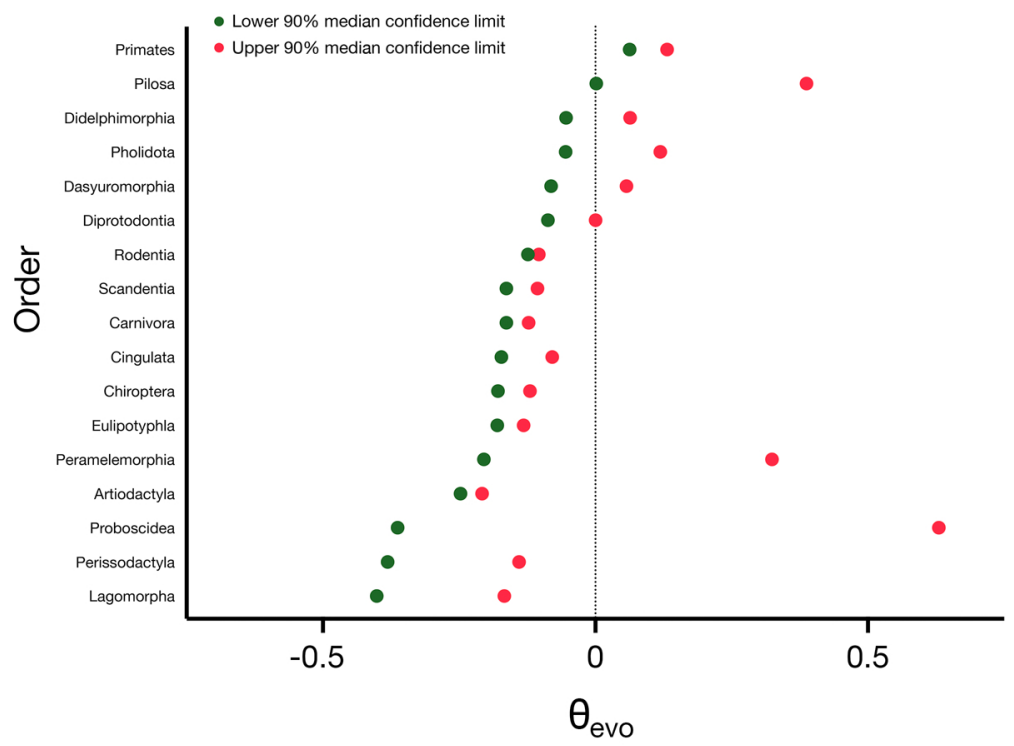

(c)

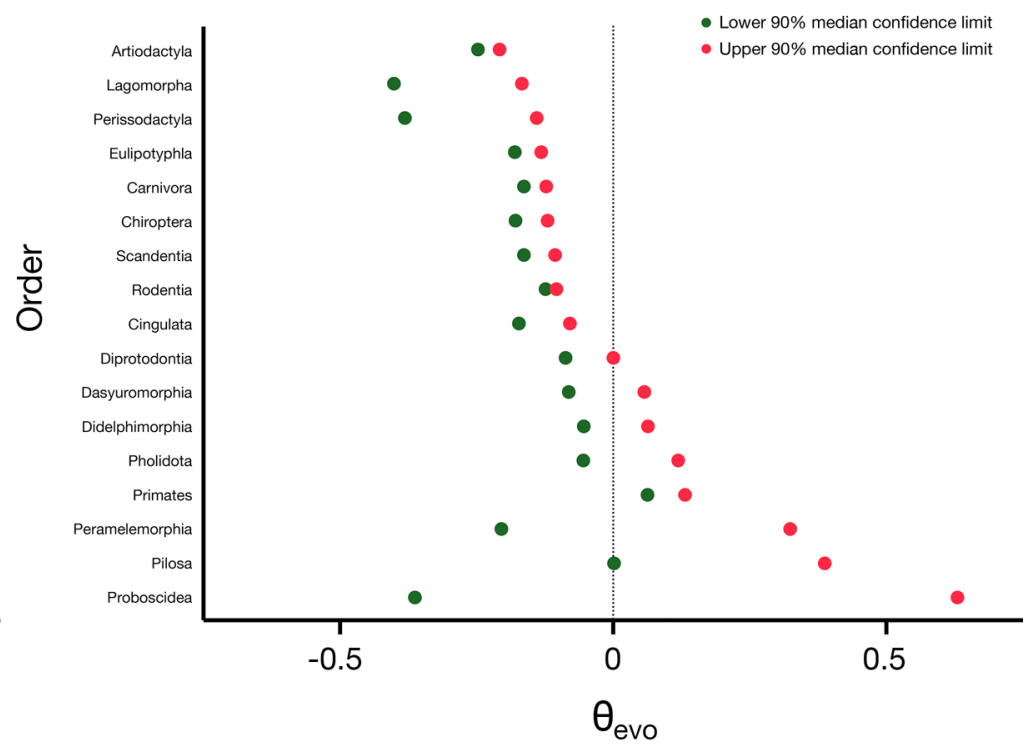

Figure 2: Mammalian orders differ in their propensity for potentially efficacious mitochondrial protein substitutions. (a) The median $\theta_{\text {evo }}$ calculated for each order assigned five or more edges is shown (vertical bar), along with the interquartile range (error bars). Lower and upper $90 \%$ confidence intervals of the median are plotted, with the orders arranged from either the highest $90 \%$ median confidence limit to the lowest (b) or arranged from the lowest upper $90 \%$ median confidence interval to the highest (c). 
(a)

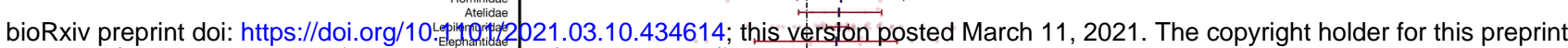
(which was not certified by peererever ew) is the author/funder "All rights reserved. No reuse allowed without permission.

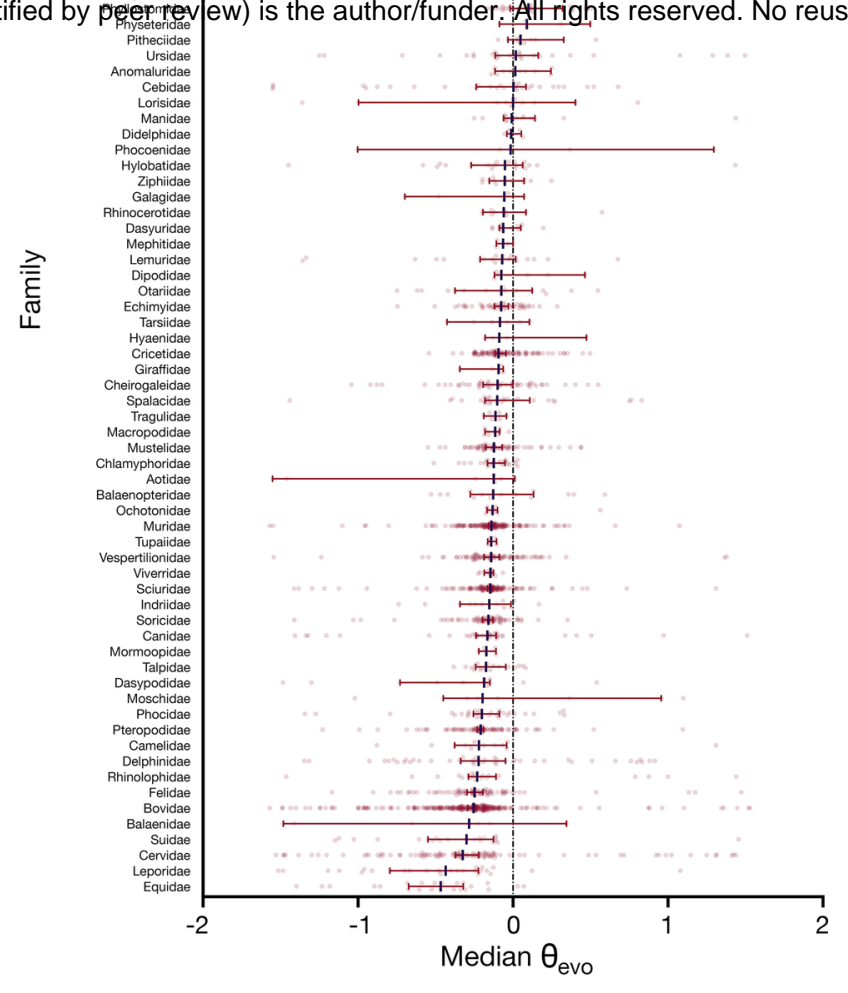

(b)

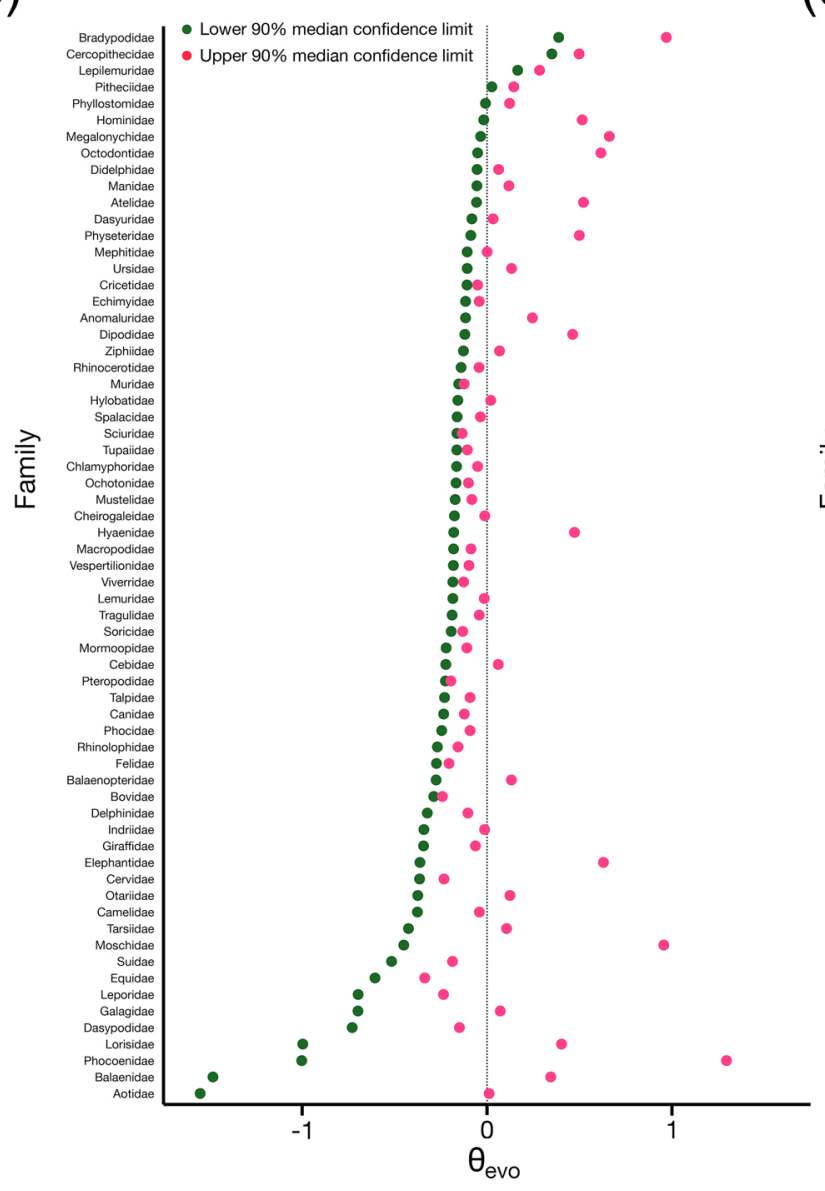

(c)

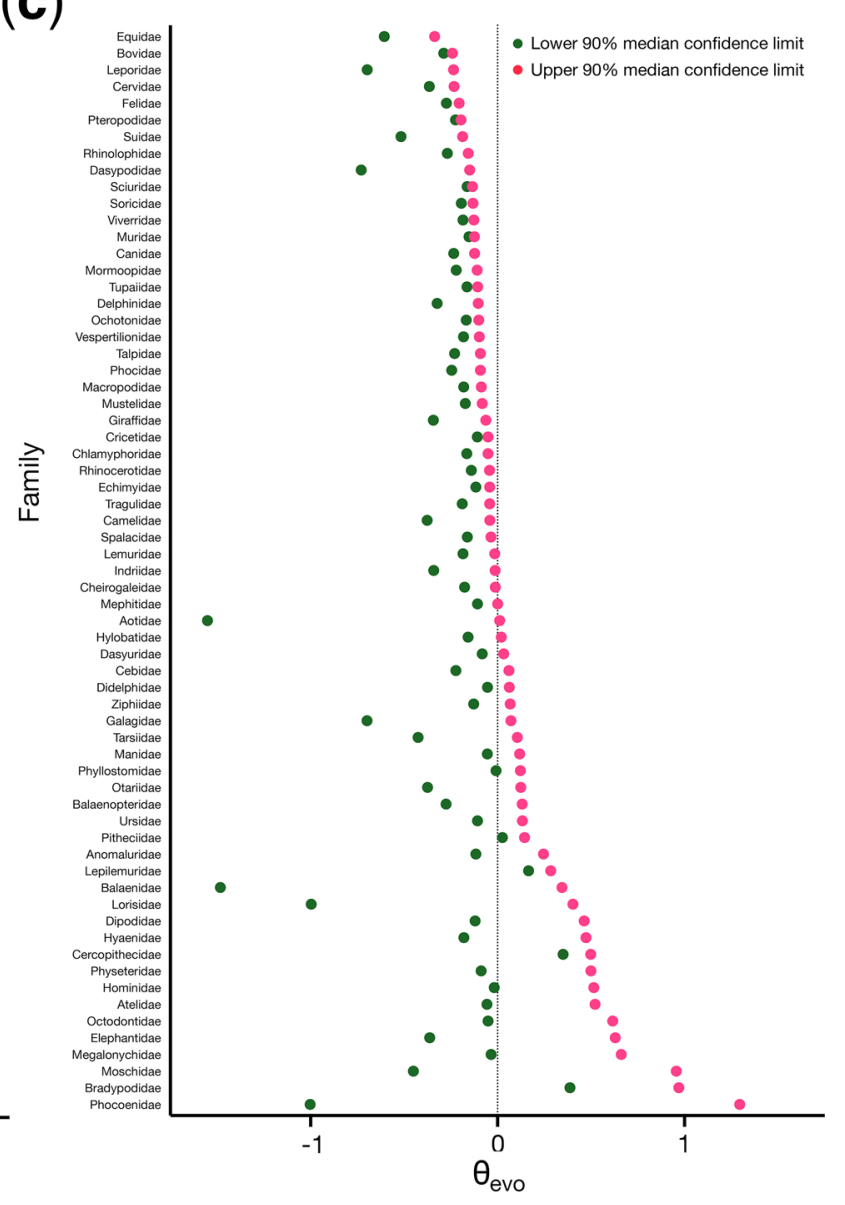

Figure 3: Mammalian families differ in their likelihood of potentially efficacious mitochondrial protein substitutions. The analyses in (a), (b), and (c) were performed as in Figure 2, except mammalian families assigned five or more edges are analyzed. 
bioRxiv preprint doi: https://doi.org/10.1101/2021.03.10.434614; this version posted March 11, 2021. The copyright holder for this preprint (which was not certified by peer review) is the author/funder. All rights reserved. No reuse allowed without permission.

(a)

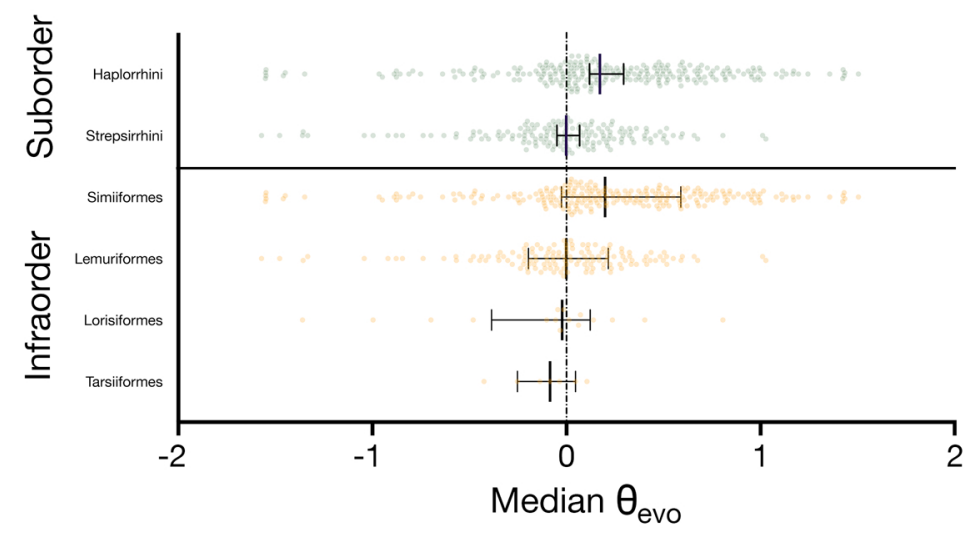

(c)

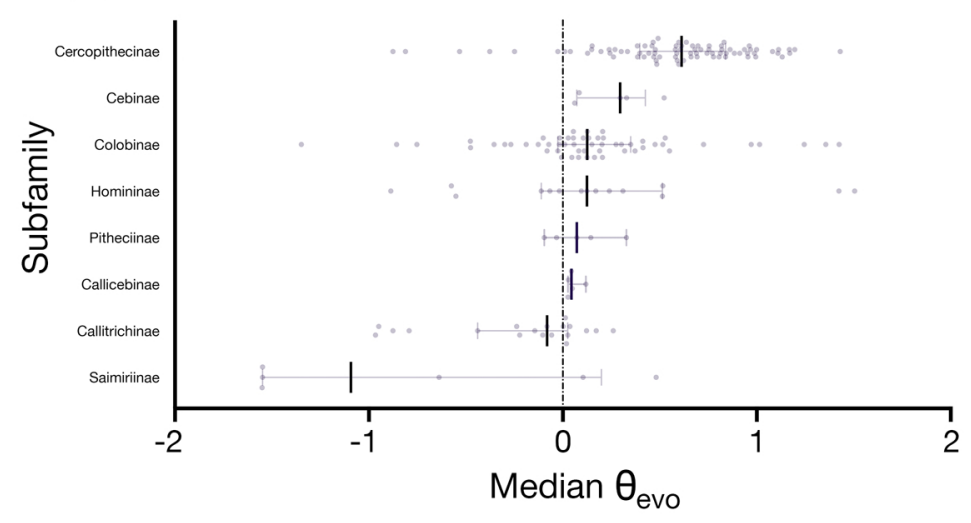

(e)

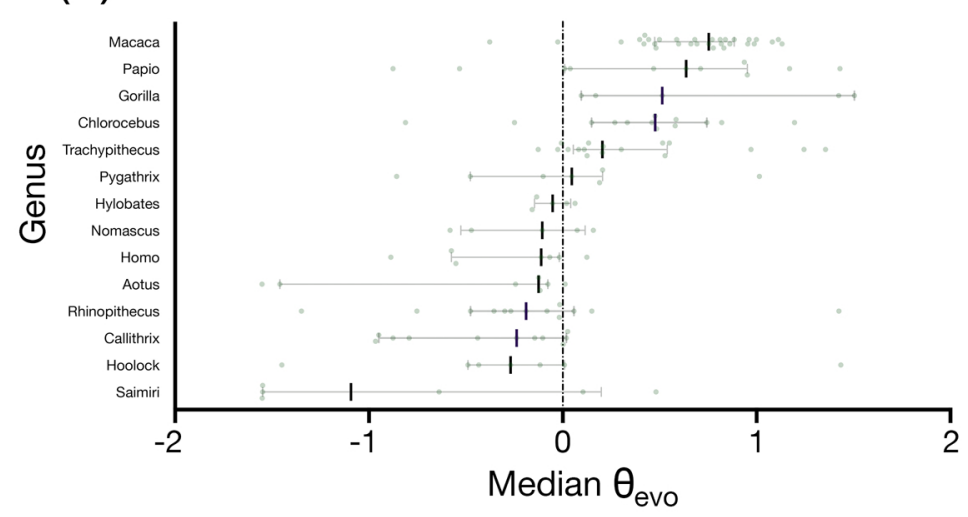

(b)

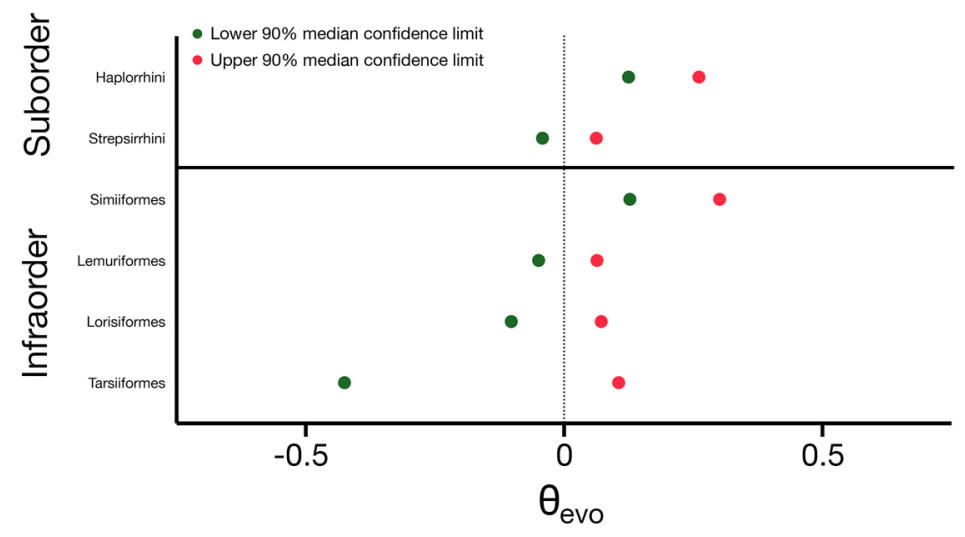

(d)
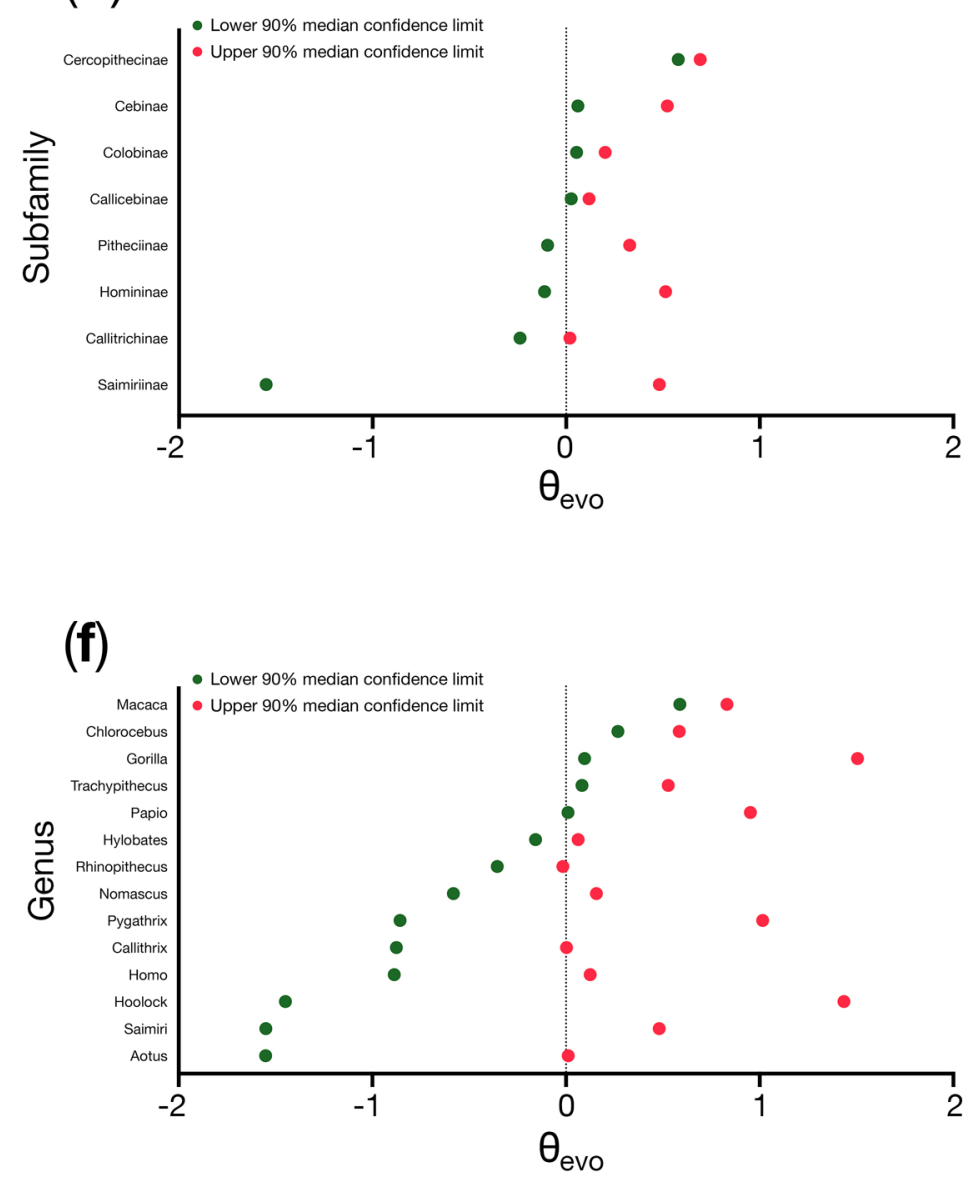

Figure 4: Substantial mitochondrial protein evolution is prevalent across several primate clades. Analyses were carried out as in Figures 2 and 3 , except primate suborders and infraorders (a and $\mathbf{b})$, subfamilies (c and $\mathbf{d}$ ), or genera (e and $\mathbf{f}$ ) assigned five or more edges are included. 
bioRxiv preprint doi: https://doi.org/10.1101/2021.03.10.434614; this version posted March 11, 2021. The copyright holder for this preprint (which was not certified by peer review) is the author/funder. All rights reserved. No reuse allowed without permission.

(a)

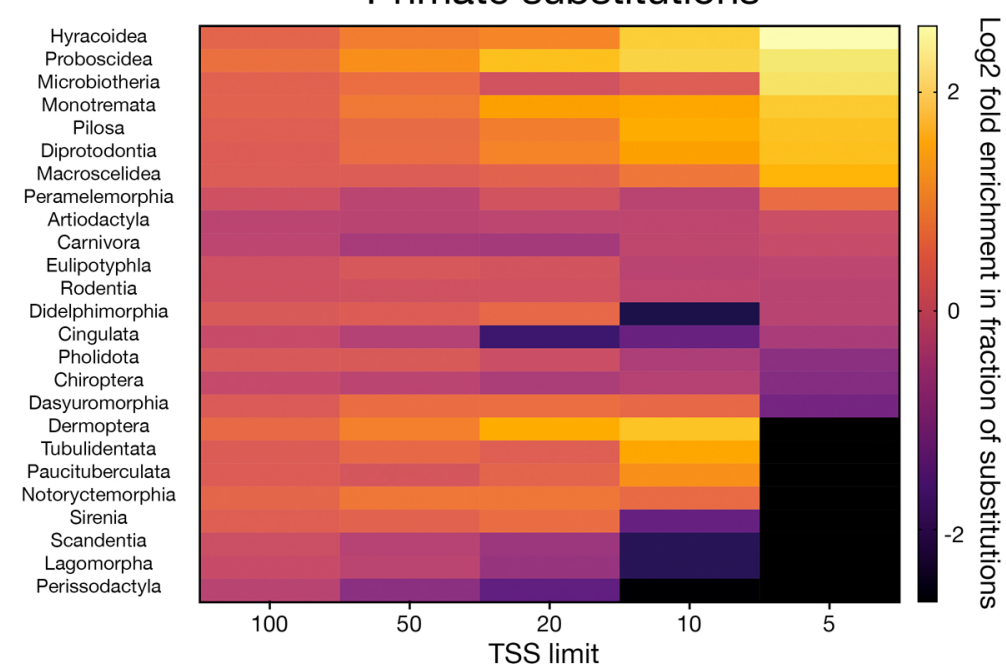

(b)

$$
\begin{gathered}
\text { Hyracoidea } \\
\text { Microbiotheria } \\
\text { Monotremata } \\
\text { Pilosa } \\
\text { Diprotodontia } \\
\text { Macroscelidea } \\
\text { Proboscidea } \\
\text { Peramelemorphia } \\
\text { Didelphimorphia } \\
\text { Carnivora } \\
\text { Artiodactyla } \\
\text { Cingulata } \\
\text { Primates } \\
\text { Rodentia } \\
\text { Dasyuromorphia } \\
\text { Eulipotyphla } \\
\text { Chiroptera } \\
\text { Dermoptera } \\
\text { Tubulidentata } \\
\text { Paucituberculata } \\
\text { Pholidota } \\
\text { Scandentia } \\
\text { Perissodactyla } \\
\text { Lagomorpha } \\
\text { Sirenia } \\
\text { Notoryctemorphia }
\end{gathered}
$$

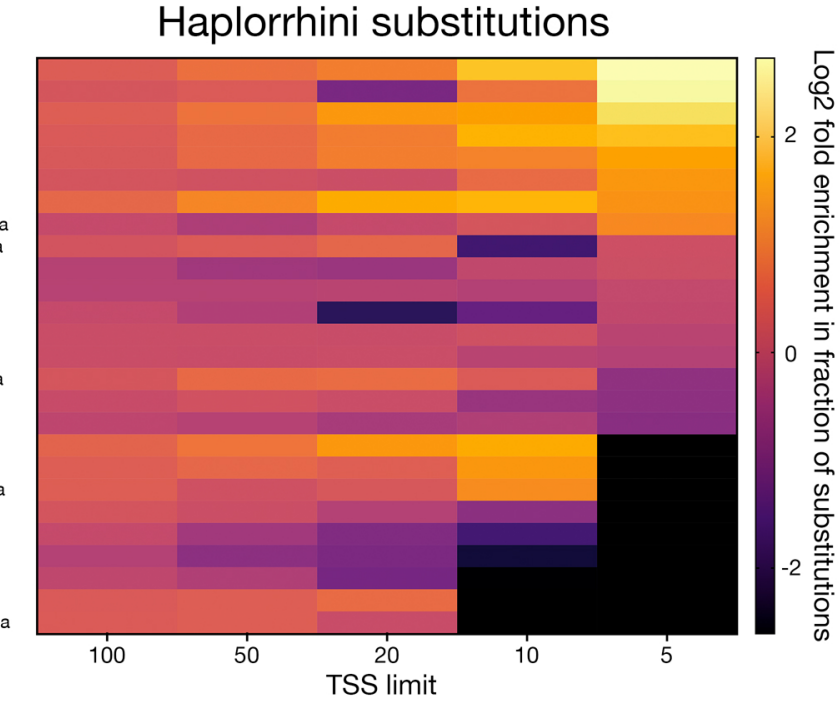

(c)

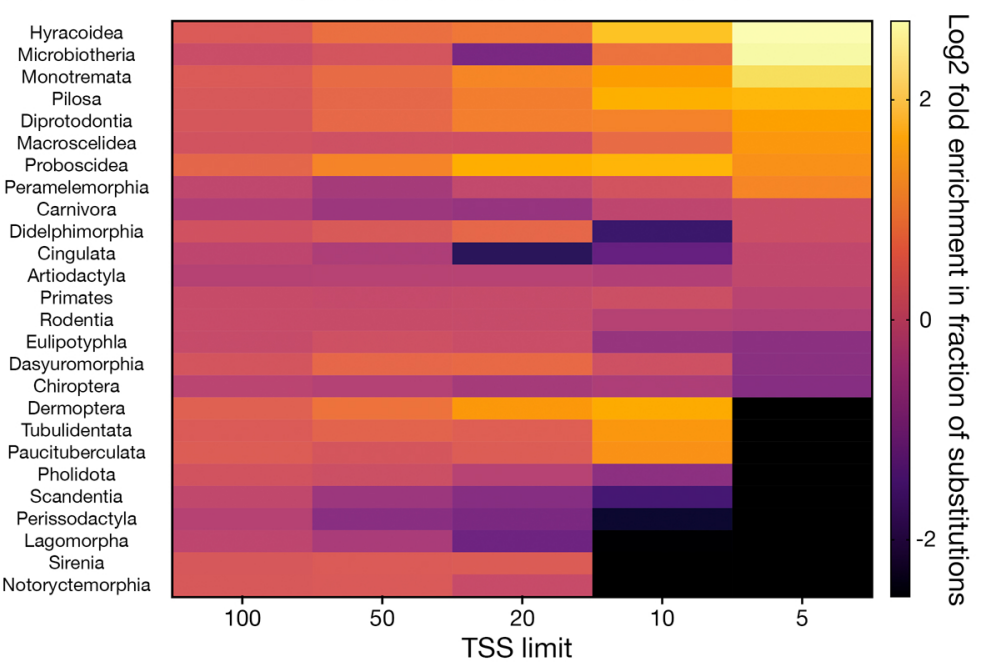

Figure 5: A search for specific primate substitutions at highly conserved mitochondrial protein positions outside of selected clades. Specific substitutions found along edges assigned to (a) primates, (b) haplorhines, and (c) simians were located in edges outside of the selected clade, and those substitutions were assigned to mammalian orders. The log2 fold change was used to compare the proportion of these substitutions found in each order when a TSS cut-off was applied to the proportion of those found in each order when the dataset was unfiltered by conservation level. 
bioRxiv preprint doi: https://doi.org/10.1101/2021.03.10.434614; this version posted March 11, 2021. The copyright holder for this preprint (which was not certified by peer review) is the author/funder. All rights reserved. No reuse allowed without permission.

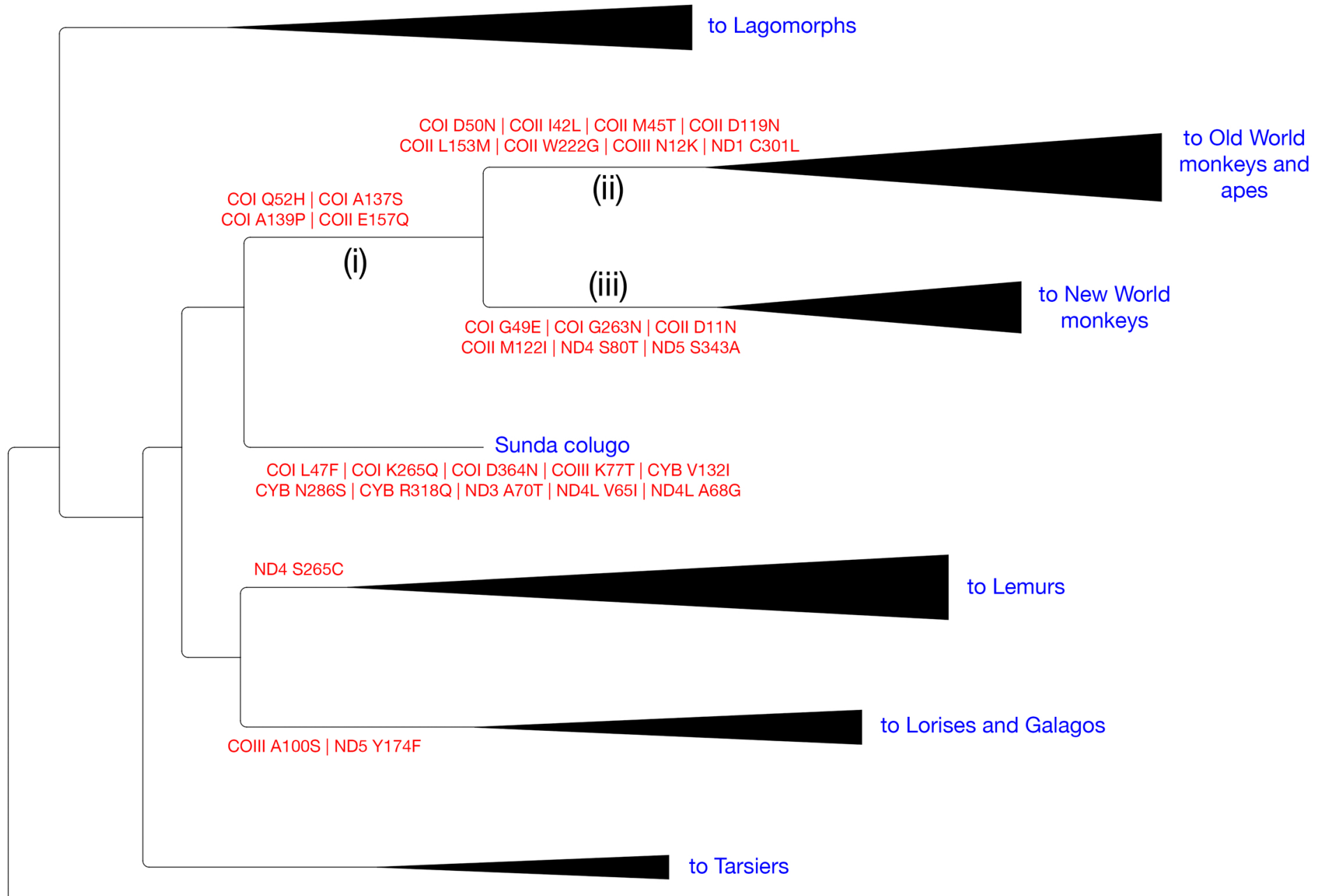

Figure 6: Substitutions at highly conserved mitochondrial protein positions are predicted at edges representing early simian evolution. A portion of the inferred mammalian mtDNA tree is provided, and all substitutions occurring at positions with a TSS of five or lower are shown. Edge (i) leads to the node parental to Old World monkeys, apes, and New World monkeys, edge (ii) leads to Old World monkeys and apes, and edge (iii) leads to New World monkeys. All alignment positions are indexed to Bos taurus reference sequences. 
bioRxiv preprint doi: https://doi.org/10.1101/2021.03.10.434614; this version posted March 11, 2021. The copyright holder for this preprint

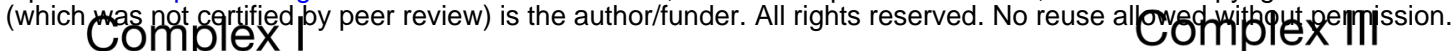

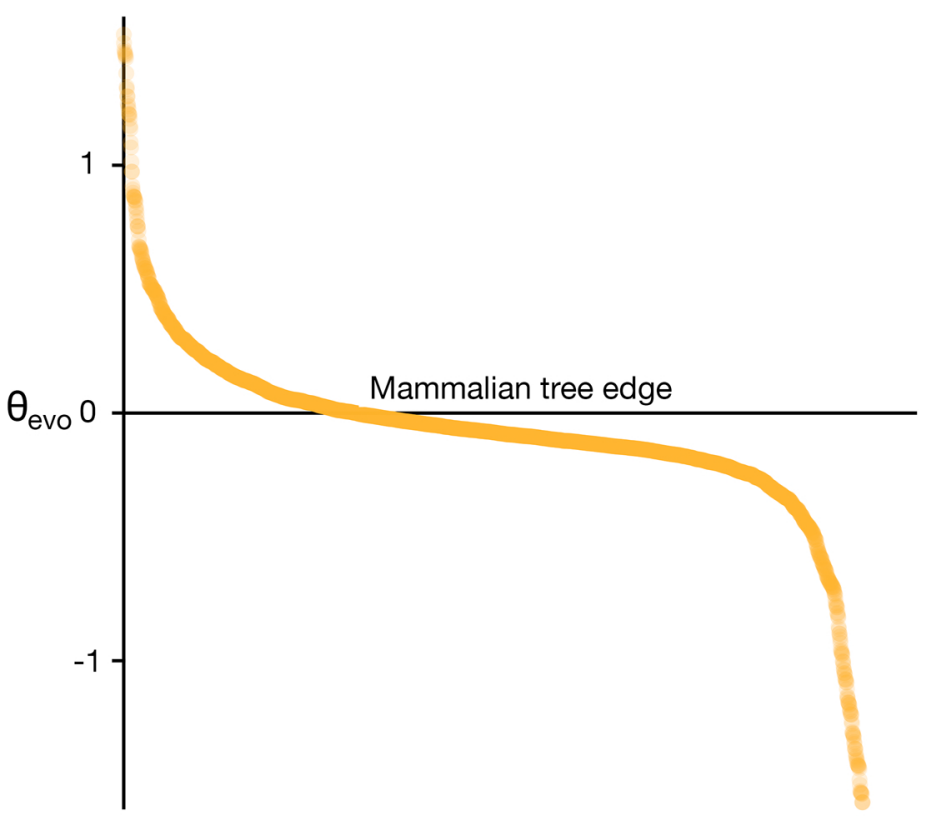

Complex IV

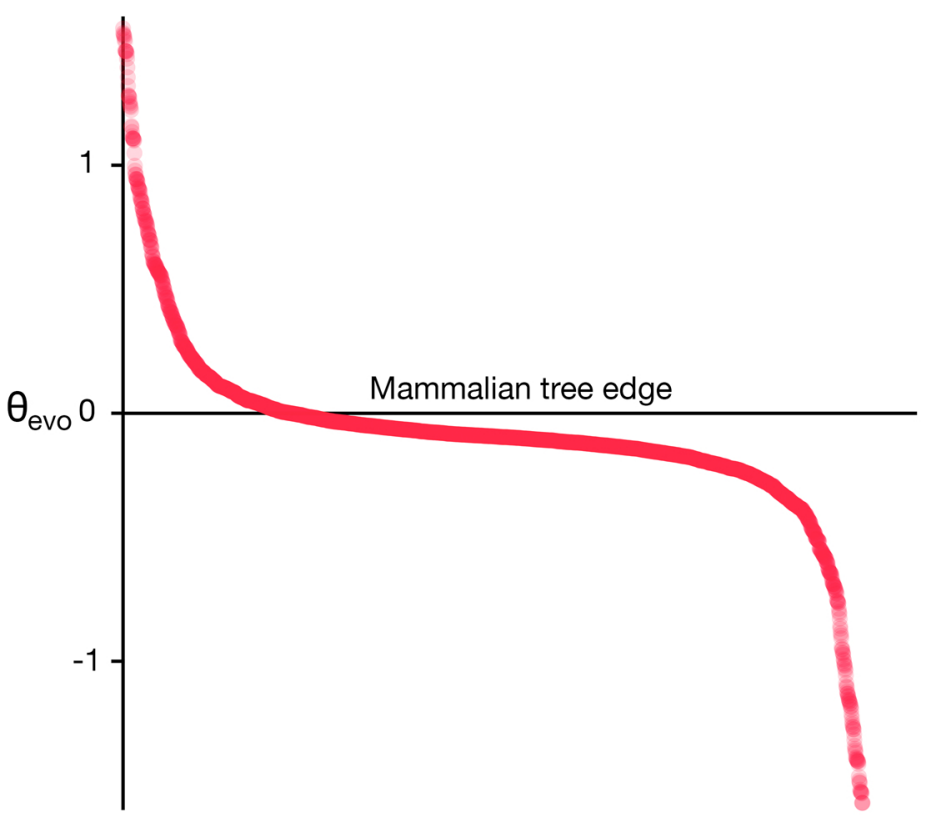

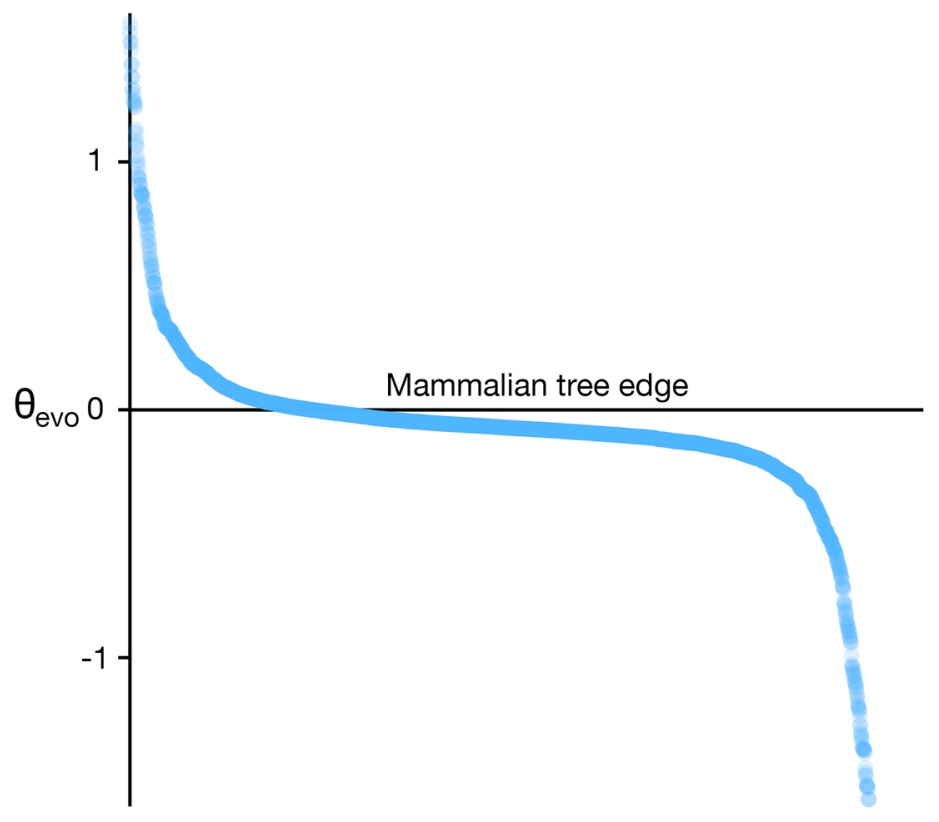

Complex V

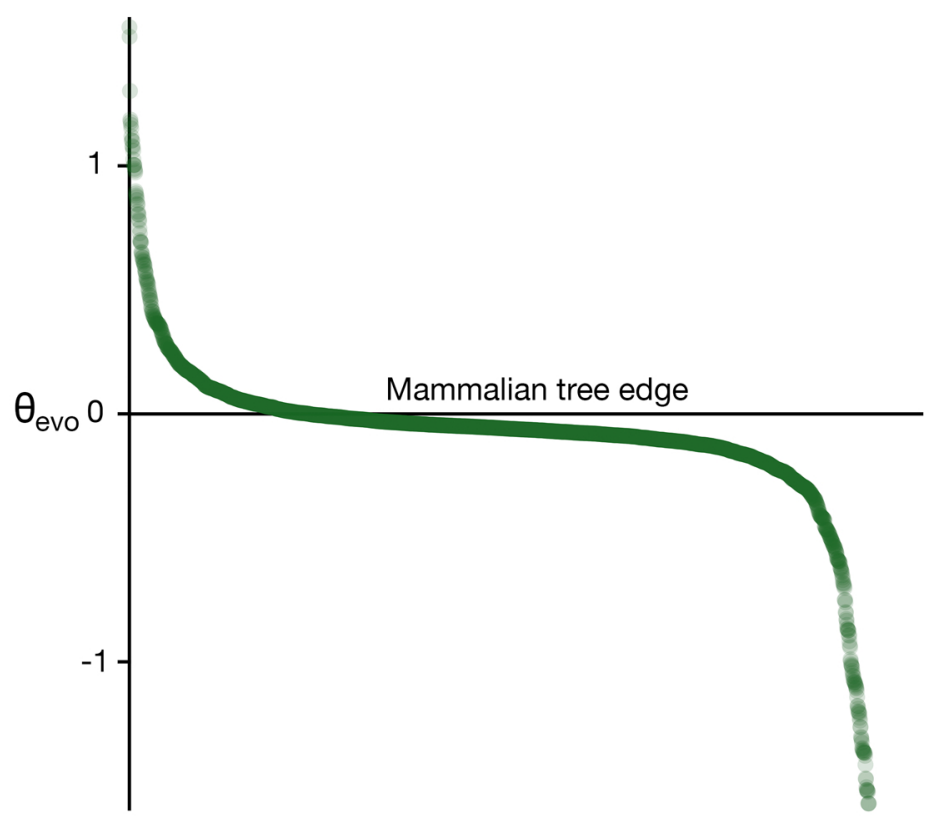

Supplemental Figure S1: $\theta_{\text {evo }}$ calculated for each analyzed edge for specific OXPHOS complexes. Analysis was performed as in Figure 1f, except that SPCSs calculated from protein positions in Complex I, Complex III, Complex IV, or Complex V were used to generate $\theta$ evo values. 
bioRxiv preprint doi: https://doi.org/10.1101/2021.03.10.434614; this version posted March 11, 2021. The copyright holder for this preprint (which was not certified by peer review) is the author/funder. All rights reserved. No reuse allowed without permission.
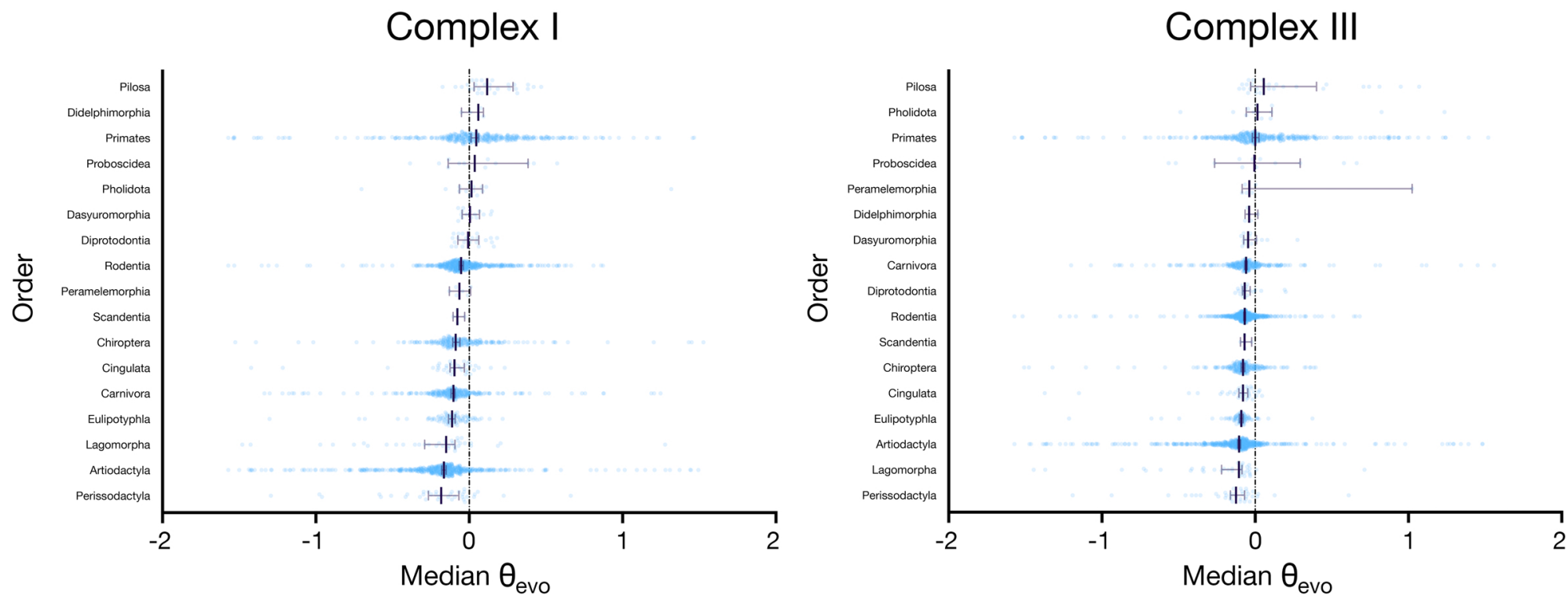

\section{Complex IV}
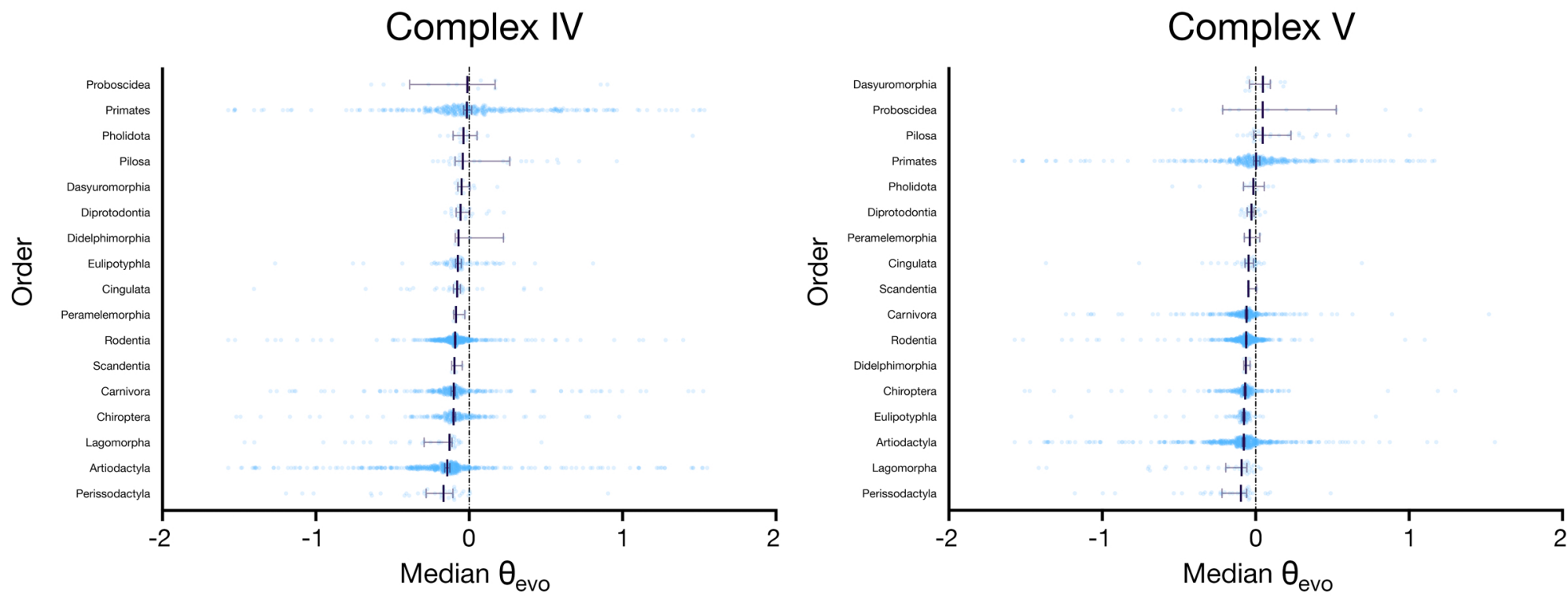

Supplemental Figure S2: Mammalian orders differ in their propensity for potentially efficacious mitochondrial protein substitutions at specific OXPHOS complexes (median calculations). Analysis was performed as in Figure $2 \mathrm{a}$, except that Өevo values were obtained by analysis of Complex I, Complex III, Complex IV, or Complex V polypeptides. 
(a)

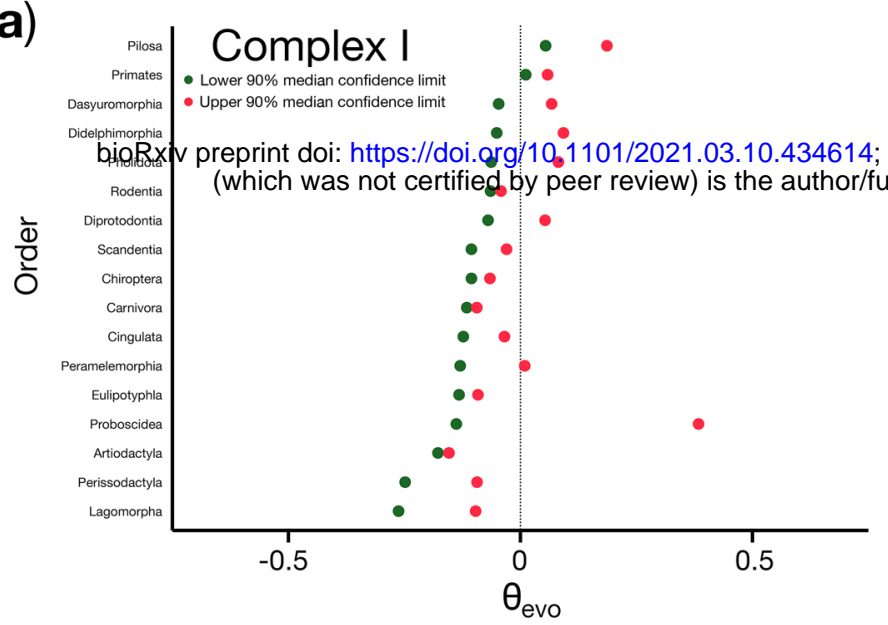

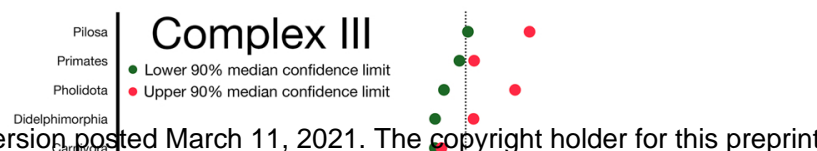
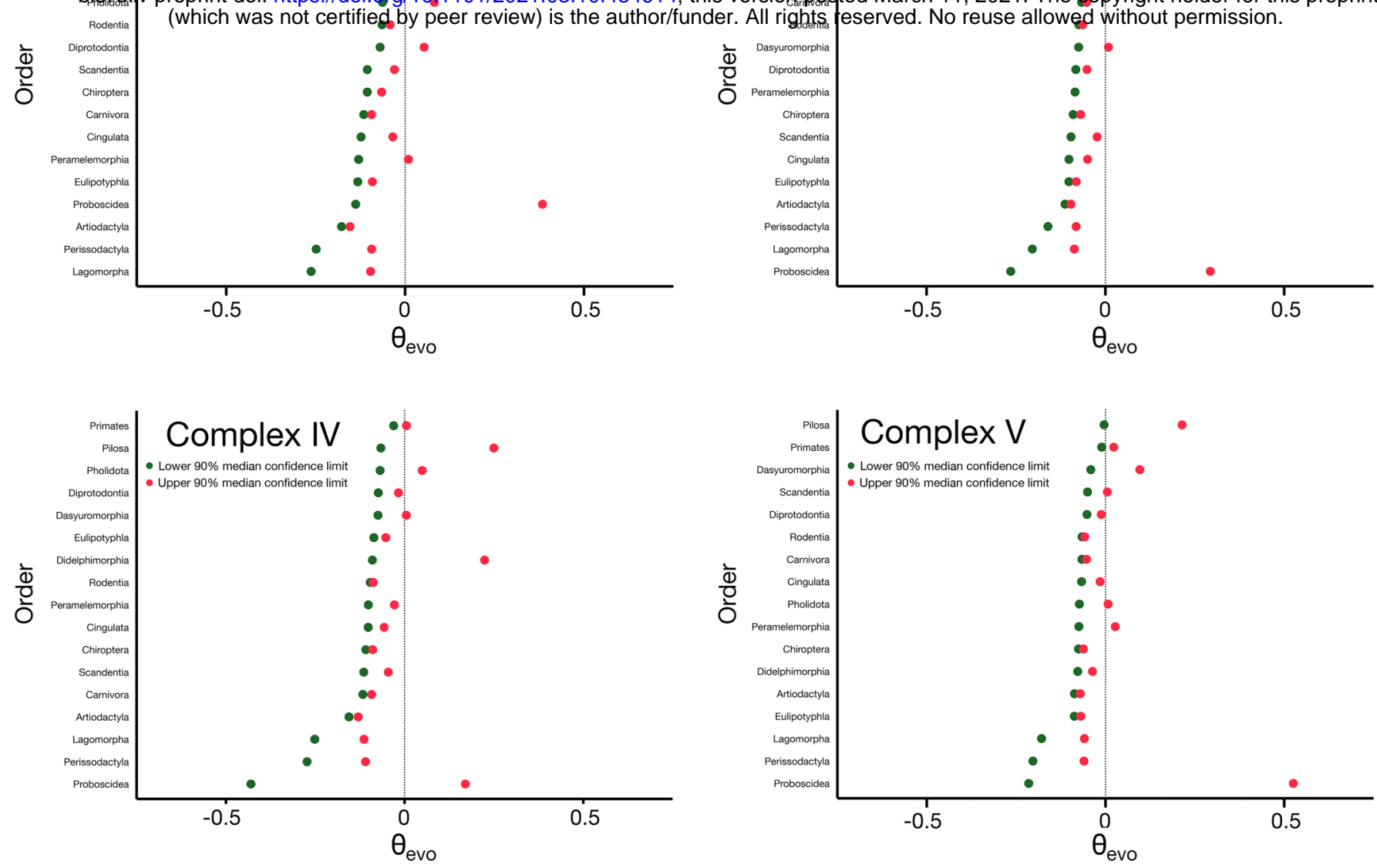

(b)
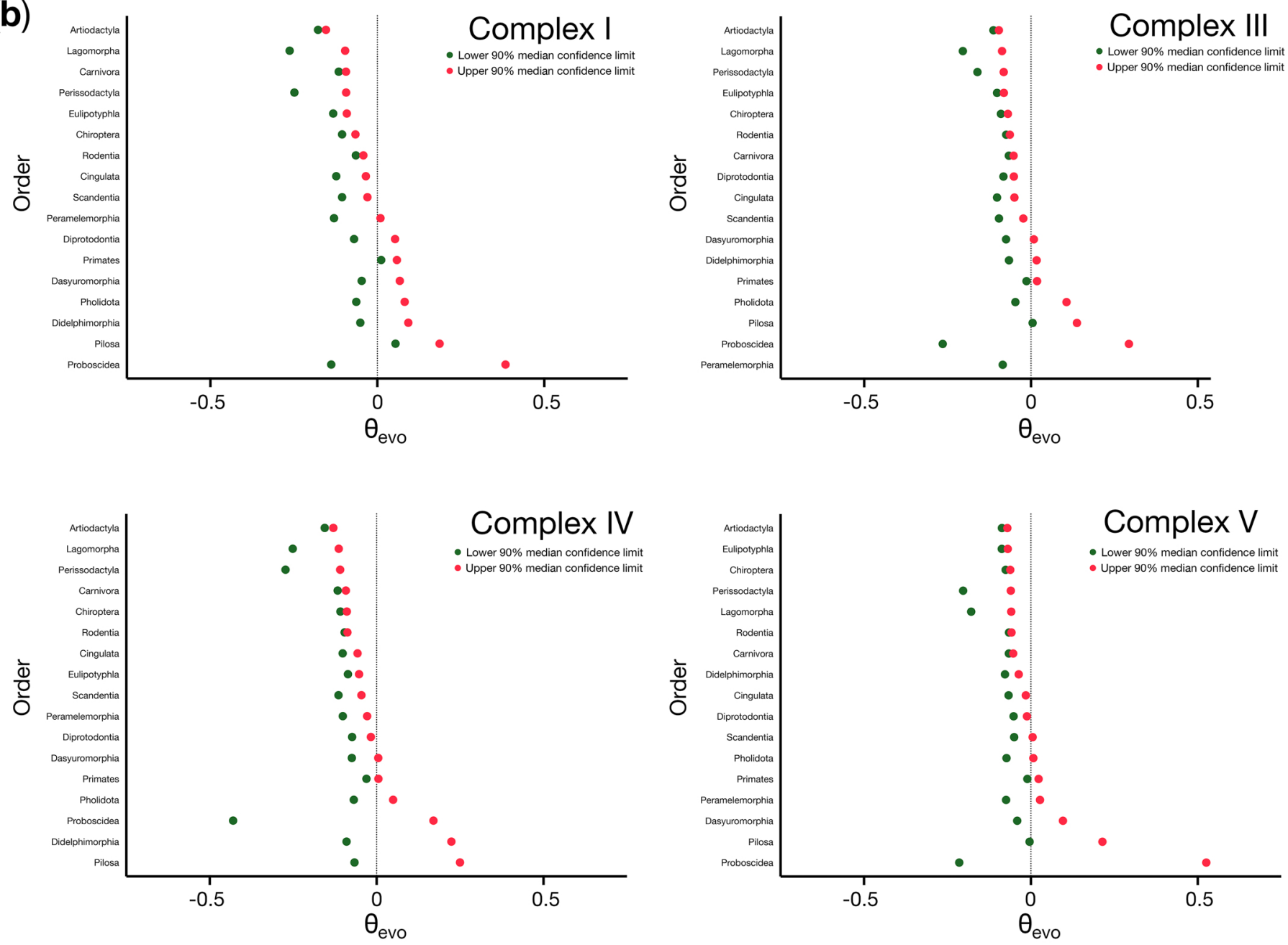

Supplemental Figure S3: Mammalian orders differ in their propensity for potentially efficacious mitochondrial protein substitutions at specific OXPHOS complexes (median confidence intervals). Analysis was performed as in (a) Figure $2 \mathrm{~b}$ or

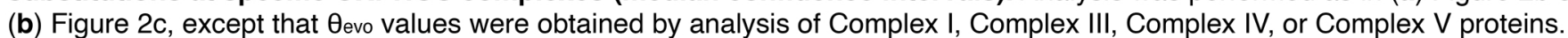





Supplemental Figure S4: Mammalian families differ in their propensity for potentially efficacious mitochondrial protein substitutions at specific OXPHOS complexes (median calculations). Analysis was performed as in Figure $3 a$,

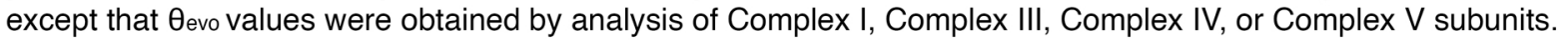



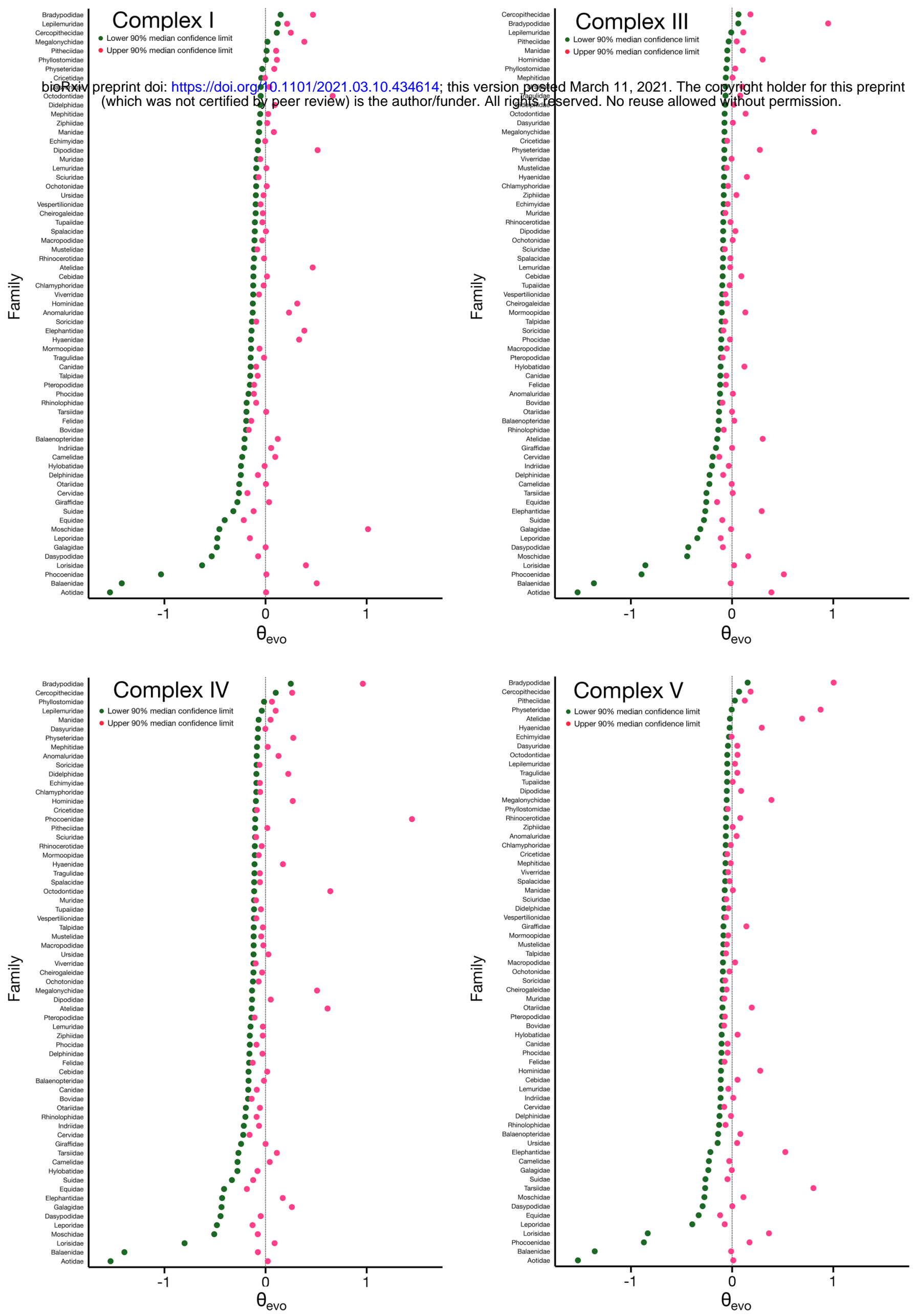

Supplemental Figure S5: Mammalian families differ in their propensity for potentially efficacious mitochondrial protein substitutions at specific OXPHOS complexes (median confidence intervals ordered by lower $\mathbf{9 0 \%}$ median confidence

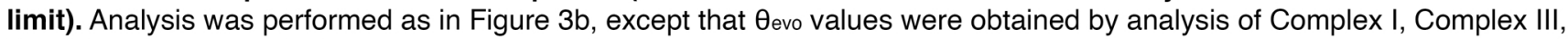
Complex IV, or Complex V proteins. 

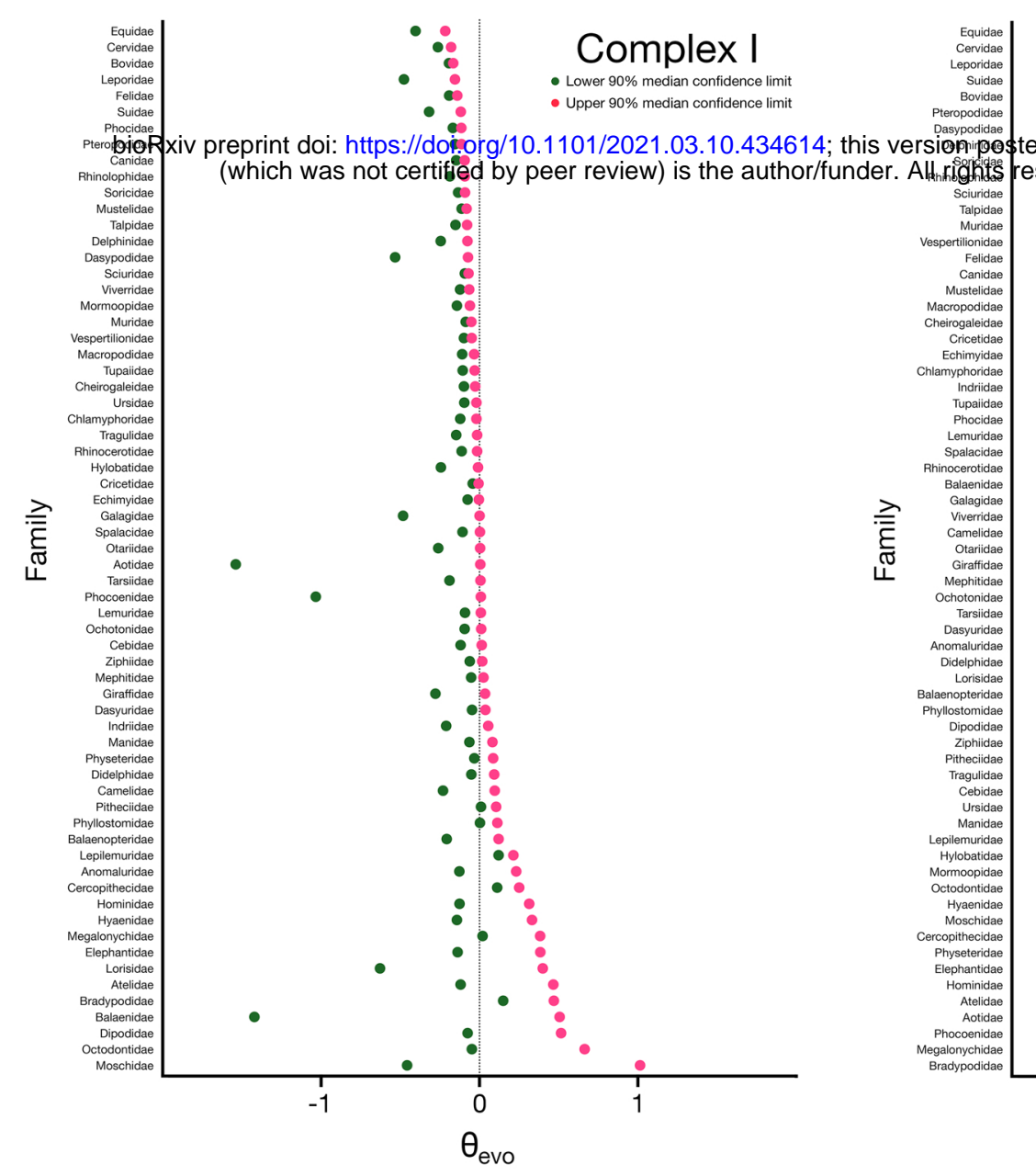

Complex III

- Lower 90\% median confidence limit

Pieropodidae

- Upper 90\% median confidence limit

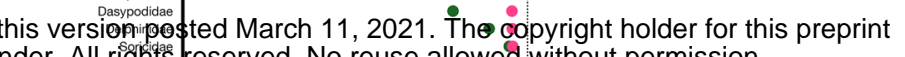

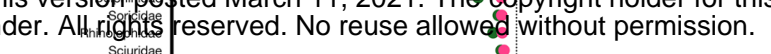
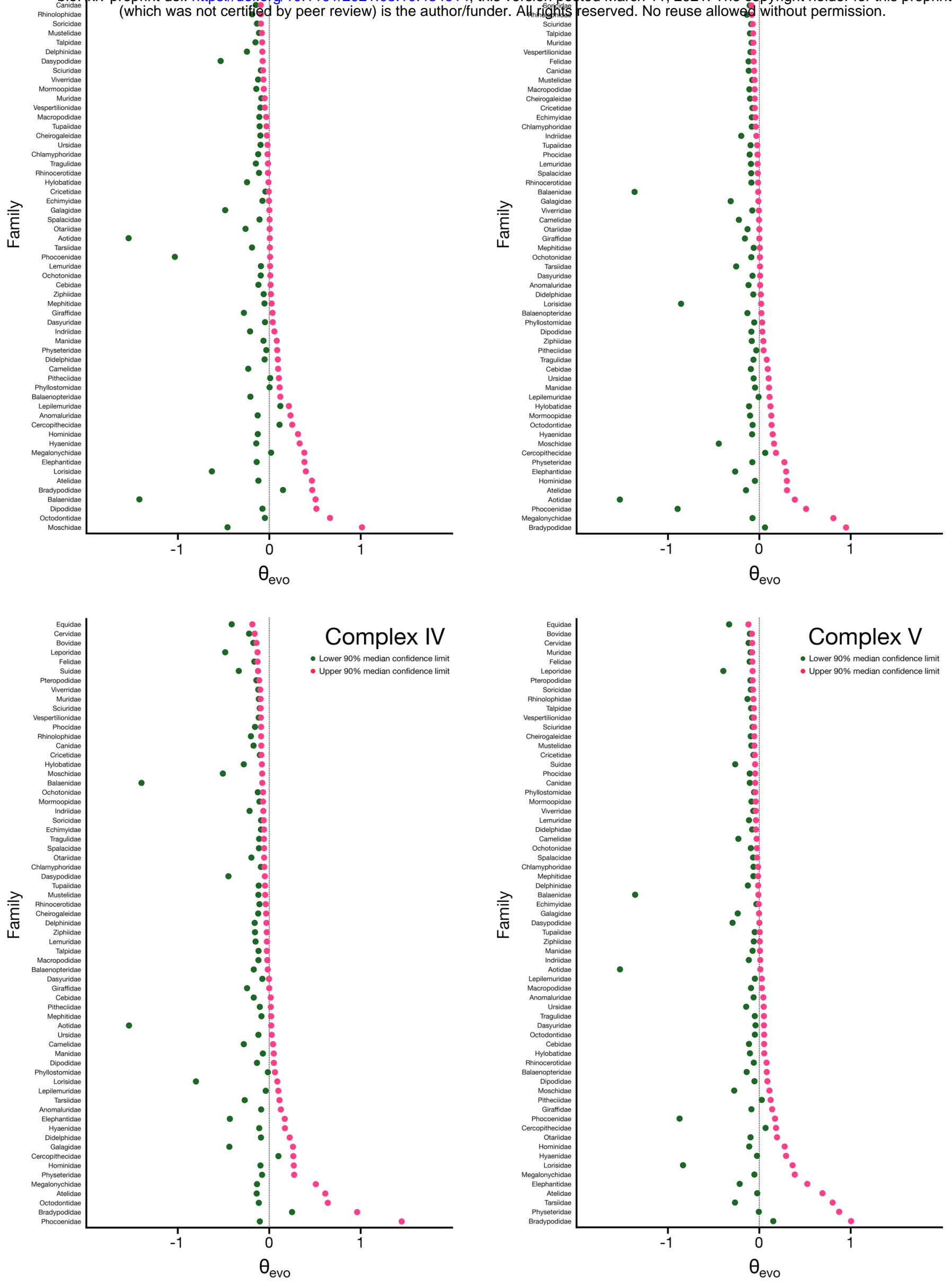

Supplemental Figure S6: Mammalian families differ in their propensity for potentially efficacious mitochondrial protein substitutions at specific OXPHOS complexes (median confidence intervals ordered by upper $90 \%$ median confidence limit). Analysis was performed as in Figure $3 c$, except that $\theta$ evo values were obtained by analysis of Complex I, Complex III, Complex IV, or Complex V polypeptides. 
biokxiv preprint doi: https://doi.org/10.1101/2021.03.10.434614; this version posted March 11, 2021. The copyright holder for this preprint Supplemaibiaw across input and ancestral sequences are listed, along with associated inferred taxonomy information, TSS, and branch length. All alignment positions refer to the Bos taurus reference sequences.

Supplemental File 2: The TSS value calculated for each mitochondrial protein alignment position using the mammalian reference sequence dataset is provided. All alignment positions refer to the Bos taurus reference sequences.

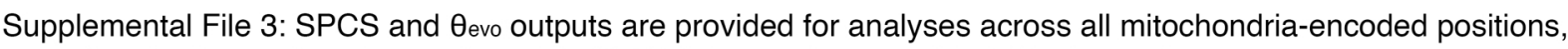
as well as for focused analyses of specific OXPHOS complexes and individual proteins.

Supplemental File 4: A GenBank flat file containing RefSeq entries for mammalian mtDNAs and the entry for the reptile Anolis punctatus.

Supplemental File 5: A maximum likelihood inferred tree generated by RAxML-NG

analysis of concatenated and aligned protein coding sequences from mammalian and Anolis punctatus mtDNAs.

Supplemental File 6: Bootstrap replicates were generated from the alignment of concatenated protein coding sequences. Felsenstein's Bootstrap Proportions (Felsenstein 1985) were calculated and used to label the maximum likelihood inferred tree of mammalian mtDNAs.

Supplemental File 7: Bootstrap replicates were generated using concatenated mammalian mtDNA coding sequences. Transfer Bootstrap Expectations (Lemoine et al. 2018) were calculated and used to label the maximum likelihood inferred tree of mammalian mtDNAs.

Supplemental File 8: PAGAN tree output using aligned amino acid sequences and the rooted maximum likelihood inferred tree as input. 